\title{
UEBER DIE \\ QUELLEN DES ZONARAS
}

roN

\section{WILHELM ADOLF SCHMIDT.}


Diese Abhandlung ist mit Genehmigung des Verfassers, Prof. Adolf Schmidt in Jena, abgedruckt aus Zimmermann's Zeitschrift für die Alterthumswissenschaft, Jahrg. 1839. Nr. 30-36.

Die Seitenzahlen des Originals sind am Rande bemerkt. 


\section{Ueber die Quellen des Zonaras.}

Der Mōnch vom Berge Athos, wenn wir dem Andreas238 Thewet trauen dürfen*), einst Grossdrungarius und erster baiserlicher Geheimschreiber, beginnt seine Chronik, welche von Erschaffung der Welt bis auf das Jahr 1118 herabreicht, mit einer gespreitzten, zum Theil höchst auffäligen Vorrede. Die Entschuldigungen über sein Unternehmen gränzen an's Fabelhafte; wir dürften sie ganz übergehen, wenn sie nicht ihn selbst und den gelehrten Zustand seiner Zeit so trefllich charakterisirten. Zonaras geht davon aus, als ob jedes profan-wissenschaftliche Thun nur ein geschäftiger Müssiggang sei und desshalb seine Arbeit ihm nicht unverdienten Tadel zuziehen könnte. In dieser Befürchtung wălzt er die ganze Schuld seines Müssigganges auf seine Freunde - als die eigentlichen Verführer (p. 1 sq. ed. du Fresue du Cange Par.) - in der That eine originelle captatio benevolentiae. Seine wirkliche oder affectirte Abhãngigkeit geht so weit, dass er sich nicht einmal getraut, selbststãn. dig ein historiographisches Prinzip aufzustellen: die guten Freunde müssen ihm darüber eine lange Vorlesung halten und vorschreiben, wie er die Sache anzugreifen habe, wie nicht. Hierbei kommen einige nicht verwerfliche Aeusserungen vor, im Ganzen ist aber das Resultat wunderlich. Sãmmtliche genera historiae conscribendae und alle bisherige Historiker werden gleichsam über die Achsel angesehen, und

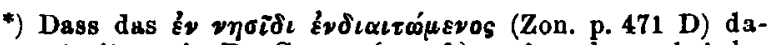
gegen streite, wie Du Cange (praef.) meint, kann bei der Natur jener Localität nicht für ausgemacht gelten. 
als ob Zonaras der erste wahre Geschichtschreiber werden sollte, wird für ihn ein Idealprincip ausfindig gemacht, das im Wesentlichen auf compendiōse Fülle hinauslăuft. Demnach hătten wir denn ein Musterbild von ihm zu erwarten (p. 2-4). Und was finden wir? Eine nach unseren Begriffen mehr als schülerhafte Pfuscherei, ein Zerrbild echter Geschichtschreibung. In Wahrheit, des Zonaras Freunde konnten, wofern sie von Fleiseh und Blut waren, keine schiefere Wahl treffen, oder - wofern nur erdichtete Reprāsentanten seiner eigenen Gedanken, keine hohlere Arroganz documentiren. Freilich fehlt Anstands halber ein gewisses Sperren und Zieren nicht, ehe die unablässig ihn

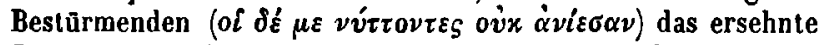
Jawort triumphirend empfangen; allein auch das ist eben nur Affectation (s. p. 4 D. - p. 5 B.). In lelzter Instanz gesellt sich ein neues Motiv hinzu. Der Mönch will nicht nur der Quälereien überhoben werden, sondern hoff auch durch sein Beginnen eine Lasterscheuche für seine schwache Tugend zu gewinnen, ein Mittel, um unnūtze Gedanken und Begierden. schmutzige und eitele Sorgen zu vertreiben

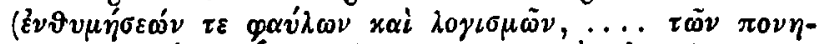

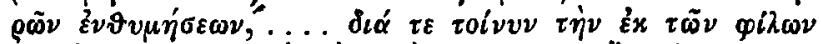

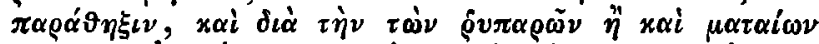

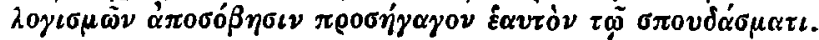
S. überhaupt p. 5), in der 'That herrliche Beweggründe der Geschichtsclıreibung. Doch lassen wir das, um auf das Werk selbst und dessen Quellen einzugehen.

239 Selten sehen wir das Studierzimmer eines Gelehrten so bücherkahl, wie das des Zonaras. Sollen wir ihn desshalb bedauern oder anklagen? Konnte er nicht, wie er wollte, oder wollte er nicht, wie er konnte? - Der hierauf bezügliche Theil des Prooemiums (p. 5 D; p. 9 D; cf. p. 471 C D) trăgt ganz den Charakter einer Elegie. Der Verfasser beklagt sich, dass er fern von dem Treiben der Welt und Sern von den reichen Schätzen der Bibliotheken, in der bittersten Armuth dasitze, beschränkt auf wenige Hülfsmittel. Also, von allen Gütern, welche die Hebel einer gelehrten Aulorschaft bilden, ist ihm nur Eins zu Theil 
geworden - die Einsamkeit, und dieses eine Gut wird für ihn gerade das schlimmste aller Uebel. *)

Es gibt nicht leicht einen Autor, der wie Zonaras einen so trefflichen Probierstein der Kritik alggäbe, und zugleich einen so lebendigen Beweis, wie leicht man in dem Urtheile über den Werth eines Sehriftstellers irren kōune, folglich wie behutsam man darin zu Werke gehen müsse.

Mag es paradox klingen, dennoch steht es fest: Zonaras taugt jetzt nur darum Etwas für den Historiker, weil er als Historiker Nichts taugt; sein Verdienst ist Verdienstlosigkeit, sein Werth ein Zufall. Wären die wenigen Quellen, aus denen er geschöpft, alle und vollständig vorhanden, so dürften immerhin die Codices desselben, bis auf die wenigen Blătter des letzten Abschnittes, wo er als Augenzeuge spricht, und welche demnach einen selbststăndigeren Werth haben, unangetastet bleiben; die Arbeit der Herausgeber würde mehr als Zeitvergeudung sein.**) Das Schicksal aber waltete anders, und wie beim Justin und manchen anderen erhaltenen Autoren sowohl des Alterthums, wie des Mittelalters, so ward auch hier die Niete zu einem nicht unerheblichen Gewinn.

Rechnen wir den besagten letzten Theil des Werkes ab, so ist Zonaras nichts weiter, als ein Abschreiber, und als solcher zeigt er sich denn auch mamentlich durchweg in den ersten zwei Drittheilen oder in den ersten zwölf Büchern nach Du Cange's Eintheilung, anf deren uăhere Untersuchung wir uns hier beschränken wollen.

Drei Principien, welche sich auf die Methode beziehen, und welche Zonaras offell als solche in der Vorrede ausspricht, müssen dem Quellenforscher als leitende Gesichtspunkte dienen: 1) Er übergeht meist die Abweichungen der Autoren, um nicht sein Werk zu sehr anzuschwellen (p. 6 A).

*) Auch diess könnte Anlass geben, seinen Aufentbalt auf dem Athos zu bezweifeln; doch war gewiss die klösterliche Bibliothek daselbst nur im theologischen Fache reichhaltig.

**) Unter solchen Umständen rechtfertigt sich daher auch das von Pertz bei den Annales Metenses und anderen Chroniken angewandte Verfahren. 
2) Er folgt seınen Quellen wörtlich (p. 6 B). 3) In den eigenen Zusătzen accommodirt er sıch dem Style der jedesmaligen Quelle (p. 6 C).

Da die Inhaltsanzeige der Vorrede (p. 6 sqq.) ausser der Anführung der Bücher der heiligen Schrift und der Antı240quităten des losephus keine directe Aứklärung ũber die Quellen des Werkes gibt: so mag hier gleich die Untersuchung der einzelnen Būcher folgen, an welche sich die allgemeineren Resultate am natürlichsten anknüpfen werden.

Die Quellen des ersten Buches (p. 13-70).

Von der Schöpfung bis auf Saul's Tod.

1) Iosephus Antıqq. L. I-VI incl. 2) Die Bücher des alten Testaments. 3) Die Chronik des Eusebius. *)

Den Iosephus citirt Zonaras selbst p. 16 G (cf. Ios. I. 1,3 ); p. 17 A (los. I. 1, 4), p. 18 D (los. I. 3, 1); p. 19 C (los. I. 3, 5); p. 19 D (Ios. I. 3, 9); p. 21 A (los. 1. 6, 1); p. 23 B C (los. I. 13, 2); p. 26 B C (Ios. 1. 20, 2. 21, 1); p. 33 D (los. II. 10); p. 35 B (Ios. II. 14, 6); p. 36 A B C (Ios. II. 16, 4. III. 1, 1 . 2. III. 1, 6); p. 42 A (Ios. IV. 4, 2); p. 45 A (Ios. IV. 8, 48); p. 46 D (Ios. V. 1, 16); p. 50 A (los. V. 4, 2); p. 64 D (Ios. VI. 10,3). Die heilige Schrift oder einzelne Theile derselben: p. $14 \mathrm{C}$; p. $15 \mathrm{C}$; p. $16 \mathrm{~A}$; p. $26 \mathrm{D}$; p. $33 \mathrm{D}$; p. 36 A; p. $42 \mathrm{~A}$; p. 45 A; p. $46 \mathrm{D}$.

Vergleichen wir den Einfluss dieser beiden Quellen, so stellt sich Folgendes heraus: Iosephus ist unbedingt und durchgehends des Zonaras Hauptrührer; denn man muss sich wohl hüten, ihn nur da als dessen Quelle zu betrachten, wo er ihn namhaft macht; unendlich oft, auf jeder Serte seines Werkes, schreibt er ihn wörtlich aus, ohne ihn zu citiren, z. B. p. $17 \mathrm{C}=$ los. $1.2,1$ u. s. w. Das Verhăltniss lässt sich genauer dahin bestımmen, dass Zonaras nicht sowohl der Bibel gefolgt sei mit Hinzuziehung

*) Wie hier, werde ich bei den meisten Abschnitten gleich rorweg die ermittelten Quellen nambaft machen. 
des Iosephus, als vielmehr dem losephus mit Hinzuziehung der Bibel. Daher ist der Gang seiner Darstellung völlig nach dem Muster des Ersteren zugeschnitten, und daher kommt es, dass er meist zunăchst die Erzălılung dieses Autors vortrăgt und dann etwa erst eine abweichende Meinung, z. B. p. $45 \mathrm{~A}$; p. $46 \mathrm{D}$; ja, er beobachtet dieses sogar auch bei solchen Punkten, wo er nicht dem losephus, sondern der entgegenstehenden Angabe beipflichtet, z. B.

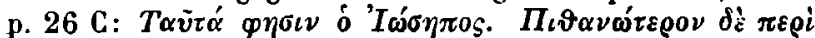

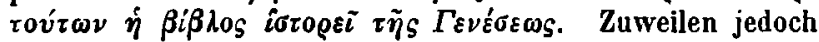
adoptirt er auch ohne Weiteres den Bericht der h. Schrift nnd bemerkt nur hinterdrein des losephus Abweichung, z. B. p. 64 D. Ueberhaupt darf man nicht in Abrede stellen, dass er die Bibel fleissig und redlich mit Iosephus verglichen; diess beweisen sowohl diejenıgen Stellen, wo er aus Jener etwas mittheilt, was dieser übergeht, wie p. 33 D aus der Genesis (cf. los. II. 10), als auch solche, in denen er Abweichungen detaillirt, z. B. p. 45 A, oder Angaben des Iosephus mit der Benerkung beibringt, dass dieselben in der $h$. Schrift sich nicht finden, wie in dem folgenden Buche p. 110 D.

Den Eusebius, welchen wir ul den späteren Abschuitten241 so hăufig zu Rathe gezogen finden, benutzt Zonaras auch schon in diesem, jedoch ohne ihn zu nennen, z. B. p. $19 \mathrm{~A}$. Hier zählt er von Adam bis zur Sūndfluth 2242 Jnhre nach Eusebius (Chron. L. post. Exord. c. 5. fin. cl. L. I. XYI. 8 sq. ed. Mai. et Zohrab.). In dem Texte des Iosephus dagegen (Antiqq. I. 3, 3) lesen wir: 2656 Jahre; wo jedoch jetzt unmassgeblich nach eingen Handschriften $\chi^{2} \lambda i \omega \nu$ für $\delta \iota \sigma \chi \iota l i \omega \nu$ zu substituiren ist, da jene Lesart durch die Angabe des mit den Iosephischen Werken so vertrauten Eusebius: secundum Hebraeorum numerum anni MDCLVl (l. c.) bestătigt wird.

Der Ausspruch des Theologen Gregorius (p. 14 B) ist eine sehr beilăutige Anführung und darf zu keinen Folgerungen Anlass geben. Ebenso wenig das Citat des Berosus, des Hieronymus und des Mnaseas (p. $19 \mathrm{C}$ ), weil es nur aus loseph. I. 3, 6 herübergenommen ist. Dagegen 
gibt dasselbe uns ein Beispiel von der groben Unwissenheit und Nachlässigkeit des Zonaras. Iosephus nennt nămlich den Mnaseas ohne Epitheton und gleich hinterher den Ni-

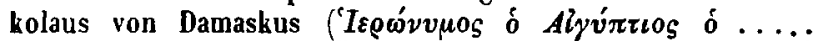

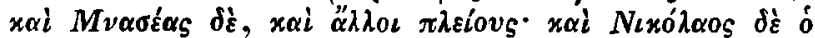

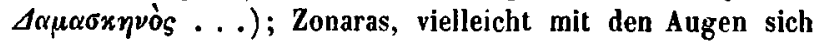
auf die folgende Zeile verirrend, macht aus beiden eine

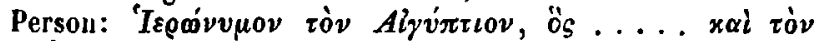

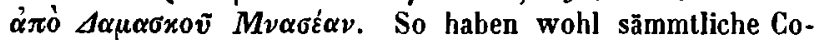
dices, und wenn dieselben auch Eine Familie ausmachen, so lehrt doch die Art der Zusammenziehung, dass diese von keinem Copisteu herrührt. Mnaseas aber, den Iosephus auch L. I. contra Ap. c. 23 citirt, war von Patara oder Patra gebürtig (cf. Voss. de hist. Gr. p. 134 sq.).

\section{Die Quellen des zweiten Buches (p. 70-116).}

Von Sauls Tode bis zur Eroberung Jerusalems durch Nebukadnezar.

1) Iosephus Antiqq. VII-X. 9. 2) Die h. Schrift.

Den Iosephus citirt Zonaras: p. 83 C D; p. 84 A D (aus ihm den Dius und Menander, ef. Ios. VIII. 5, 3); p. 86 B; p. 109 C; p. 110 D (cf. Ios. X. 1, 4, woraus auch die Erwāhnung des Herodot entlehnt ist); p. 111 A (cf. 242Ios. X. 1, 4, 5, hieraus den Berosus. Durch diess Citat des Zonaras fällt auf die nur schembar verdorbene Stelle des losephus ein bedeutendes Licht, was dessen Herausgeber sämmtlich übersehen zu haben scheinen). Die $h$. Schrift wird citirt: p. 83 D; p. 84 A; p. 86 B; p. 110 D.

Die Quellen des dritten Buches (p. 116-169).

Von der Eroberung Jerusalems durch Nebakadnezar bis auf den 'Tod des Cyrus.

1) Iosophus Antiqq. X. 9 bis zum Ende des Buches. 2) Die h. Schrift. 3) Theodoret. 4) Plutarch. 5) Xenophon. 6) Herodot.

Das dritte Buch zerfâllt seinem Inhalte nach in zwei 
Theile, welche sich da abgrănzen, wo die Geschichte der Perser beginnt, p. 146. Hiernach richtet sich naturgemãss unsere Untersuchung.

\section{Erste Hälfte (p. 116-146).}

Bis auf den Tod des Tobias.

Von p. 116-119 B sind losephus (Antiqu. X. 9 iu. $-10,5)$ und die Bủcher der $h$. Schrift des Zonaras alleinige Führer. Dagegen låsst er bei der Erklärung von Nebukadnezars Traum p. 119 B-p. 121 B den Iosephus ganz bei Seite liegen; denn dieser geht nicht nur auf keine Interpretation der Daniel'schen Traumdeutung über die Reiche der Erde ein, sondern theilt nicht eimmal die Deutung selbst vollstăndıg mit; vielmehr schliesst er mit der Herrschaft des vierten Reiches, welches, dem Eisen gleich, die römı-

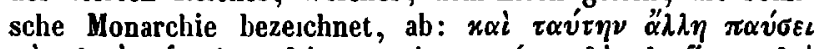

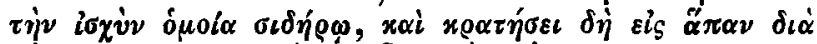

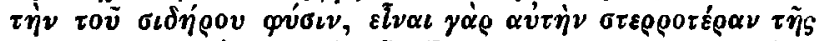

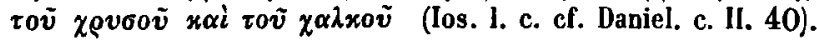
Die Absicht, wesshalb losephus den Rest der Prophezeiung verschweigt, betreffend den Stein, der Eisen, Erz, Silber und Gold zertrümmert und eine ewige Herrschaft, die des Christenthums, andeuten soll (Daniel. Il. 41-45), liegt klar am Tage. Sicher sah er nicht in dem Steine das Sinnbild des damals eben erst aufkeimenden Christenthums oder überhaupt einer geistıgen Weltherrschaft, soudern hătte von seinem Standpunkte aus ihn nur auf eine materielle, irdlsche Macht beziehen können. Dann würde er aber die Vernichtung des römischen Heiches haben prophezeihen müssen. Und was hătte Rom dazu gesagt und das Flavische Haus, dessen Schützling er war? Aus dieser Verlegenheit konnte nur Schweigen ihn retten; allein eine Unterlassungssünde243 wollte er gerade auch nicht begehen, und so sucht er denn auf eine höchst charakteristische Weise allen Anfechtungen durch eine plötzliche feine Wendung zu entschlüpfen. $z \delta \eta^{\prime}-$

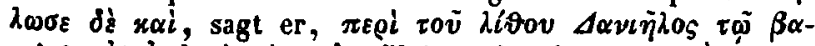

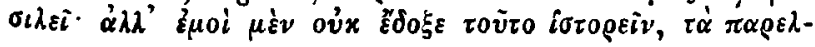




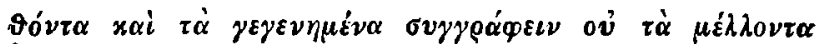

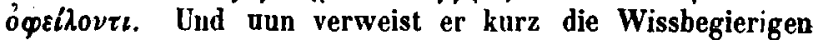
auf den Daniel selbst (X. 10, 4 fin.). - Ganz anders macht es natürlich der Mönch des zwölften Jahrhunderts, obgleich der Umstand, dass er die Prophezeiung gerade da unterbricht, wo Iosephus sie schliesst, hinlänglich darthut, dass er bis dahin noch immer nur diesen vor Augen hatte und dessen Plane folgte. Zonaras erkIărt zunächst die vier weltlichen Reiche auf die bekannte Art für das assyrische, das medisch-persiche, das macedonische und das römische; hierauf geht er, mit Hinzufügung des Restes der Prophezeiung aus Daniel, zu dem Symbole des Steines über und wendet es mit Ausführlichkeit auf Christus und dessen Stiftung an. Ist nun aber der Inhalt dieses Abschnittes wirklich einer der wenigen selbstständigen Zusätze, wodurch Zonaras gleichsam fremdes Eigenthum interpolirt? Zwar deutet er nicht im entferntesten eine besondere Quelle an, auch ist der schriftstellerische, sowie der absolute Werth des Einschiebsels nur gering, da in seiner Zeit jene Erklårung găng und găbe war, wăhrend auch die unserige sie schon aus seinen Vorgāngern vollstăndig keunt. Dennoch ist er auch hier nicht einmal unabhăngig, sondern erborgte das Wesentliche aus einem Schriftsteller, den er in den ersten 12 Büchern niemals nennt, aus Theodoret's Commentar zum Daniel, obgleich nicht durchaus wörtlich und nicht ganz ohne eigenes Räsonnement. Genauere Vergleichung: Zon. p. 119 B -C med. aus Theod. Comm. in Dan. c. II, v. 31-33. Opp. omn. T. II. P. Il. ed. Schulze p. 1089 sq. ; ed. Sirm. p. 563. - Zon. p. $119 \mathrm{C}$ med. -120 B fin. nach Theod. p. 1095-1099 (die politischen Ausführungen über Hom sind meist eigener Zusatz, aus der Lectüre abstrahirt; dess-

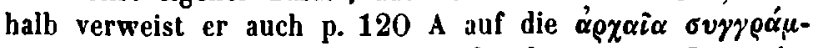
$\mu \alpha \tau \alpha$, was nicht mehr bedeutet, als ob er sagte: Das weiss Jeder, der die römische Geschichte kennt, der den Dio oder einen ăhnlichen Historiker gelesen). - Zon. p. $120 \mathrm{C}$ p. 121 A fin. nach Theod. p. 1092 sq., aus dem auch die anscheinend selbstständigen Citate der Schriften des alten und neuen Testaments sämmtlich entlehnt sind. 
Von p. 121 B-p. $124 \mathrm{D}$ fin. schreibt Zonaras wieder wörtlich den losephus (X. 10, 5-11, 7) ab; selbst der

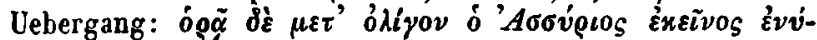

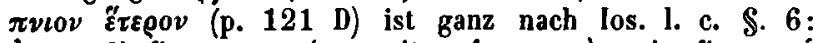

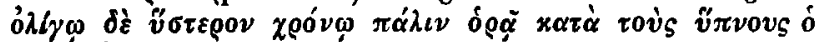

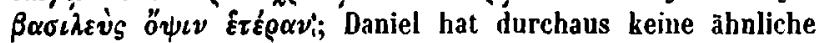
Aeusserung. Nur bei Gelegenheit der Traumdeutungen ergănzt er neuerdings seiuen Hauptführer aus Daniel c. IV. Namentlich citirt er den Iosephus p. $122 \mathrm{D}$; und aus ihm den Berosus, Megasthenes, Diokles und Philostratus, den Verfasser indischer und phönicischer Geschichten (cf. Ios. X.

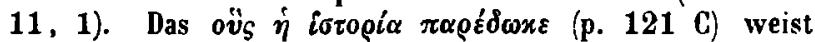
auf Niemand anders als Iosephus (X. 10, 5) und Daniel (c. III). P. $124 \mathrm{~A}$ hat Zonaras einige Angaben über Cya-244 xares, die sich weder beim Iosephus noch im Daniel finden.

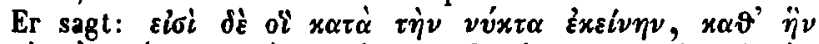

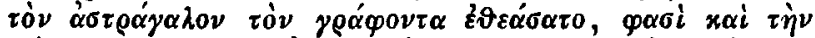

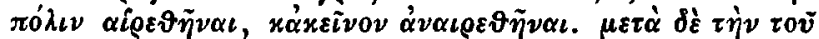

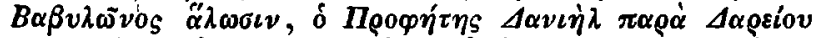

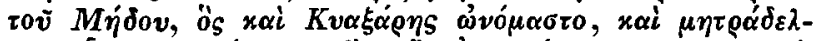

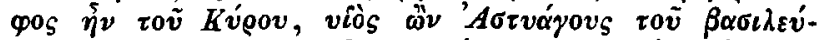

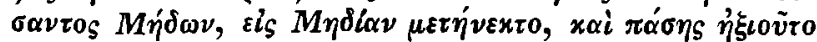
$\tau \iota \mu \eta_{s}$. Zonaras muss hier also einen andern Gewährsmann haben; die Vermuthung führt uns wieder auf die Cómmentare zum Dauiel. Und in der That, wir finden im Theodoret (in Danjel. VI. p. 616 ed. Sirm., p. 1173 ed. Schulze) dieselbe Angabe; ohne $Z$ weifel hat ihn Zonaras also auch hier benutzt. Zwar beruft sich Theodoret selbst bei jener Behauptung auf Iosephus; doch fehlen bei diesem (X. 11, 4) einige Momente, besonders der Name Cyaxares.

Der Abschnitt von p. 124 D-p. 138 C med. enıhält249 die Visionen und Revelationen des Daniel. Iosephus (S. X. $11,7)$ berührt dieselben wieder nur obenhin; der Mönch musste natürlich ein grösseres Wohlgefallen daran finden. Seine Hauptquelle ist Daniel c. VII-IX. Nur die in diesen Capiteln enthaltenen Geschichten theilt Zonaras ausführlich mit; die übrigen deutet er bloss durch Hinweisung auf das Buch des Propheten an (p. 138 B C). Bei der genauen 
Interpretation aller Einzelheiten hat er wiederum den Commentar des 'Theodoret (s. p. 1190-1252 ed. Schulze) zu Rathe gezogen. Zwar erwähnt Zonaras gerade ihn nicht, sondern sucht vielmehr durch manuichfache andere Citate eine grosse Belesenbeit zu affectiren; er nemnt den Plutarch (p. 127 A), den Dio Cassius (p. 127 C), den Polybius (ibid.), melirere einzelne Schriften des alten und des neuen Testaments (p. 134 A B p. 135 B) und den losephus (p. 136 B);

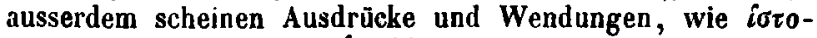

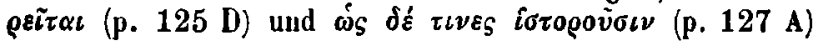
auf besondere Quellen zu deuten. Allein, abgesehen von der Anführung des Dio und des Polybıus, welche nur eine ganz allgemein gehaltene Hınweisung auf deren Werke überhaupt ist, von keınem, grōsseren Gewicht, als der oben be-

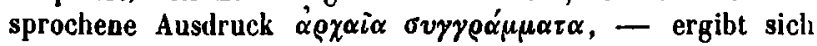
höchstens das Citat des Plutarch als selbststăndig; die übrigen sind sammt und sonders erborgt. Man sehe die năhere Vergleichung:

Zon. p. 125 A-B fin. ist nach Theod. p. 1190 sqq.

, p. 125 B fin. $-D$ fin. aus Plut. Artax. c. 16.

" p, 126 A -127 A nach Theod. p. 1192 sqq.

" p. 127 A mit dem unvollständigen Citate : $\varphi \eta \sigma i$ yá $\varrho$ o $X \alpha \iota \rho \omega \nu \varepsilon v_{\zeta}$, ist eiue wörtliche Entlehnung aus Plut. Alexand. c. 77 fin.; auf diesen geht auch das

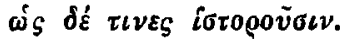

" p. 127 A med. -129 B med. nach Theodor. p. 1195-1201, mit jenen beiläufigen Verweisungen auf Dio und Polybius.

$250 "$ p. 129 B med. $-132 \mathrm{C}$ med. nach Theodor. p.
$1212-1220$, mit einigen Ergănzungen aus eigenem durch Lectüre des Plutarch und des Iosephus gewonnenen Wissen.

, p. $132 \mathrm{C}$ med. $-138 \mathrm{~B}$ med. nach Theodor. p. 1237 -1252 cl. p. 1225 . Die hierhergehörıgen Citate aus der heiligen Sclhrift p. 134 A B und p. 135 B sind genau aus Theod. p. 1241 sq. und p. 1244 herübergenommen. Ja, nicht einmal die Berufung anf losephus p. $136 \mathrm{~B}$ ist eine unmittelbare, son- 
dern fliesst ebenfalls aus Theod. p. 1246. Diess ist nicht zu verwundern; denn sie bezieht sich auf eine Angabe desselben in den späteren Büchern, die lim noch nicht vor Augen lagen.

Mühsam etwas vorweg aufzusuchen, ist nãmlich durchaus nicht des Zonaras Art; er glaubt schon genug zu thun, wenn er hier und da einer Curiosıtăt halber eimen ausserordentlichen Weg einschlăgt, den er nıcht die Absicht hat anderwärts weiter zu verfolgen. Dahin gehört nun auch

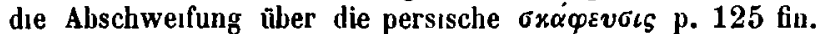

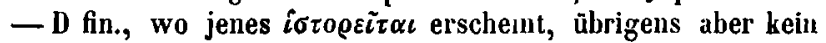
Gewăhrsmann genanut wird. Dass die Beschreibung aus dem Artaxerxes des Plutarch entlehnt sei, benerkte ich oben schon; auch Du Cange nahm es wahr (s. T. II. not. hist. p. 9. Diess ist bei ihm en seltener Fall). Die Abweichung, dass Zonaras den Mitbridates, den er nicht namhaft macht, 14 Tage martern lässı, während Plutarch von 17 Tagen spricht, kann keinen Austoss geben; sie ist auf verschiedene Weise erklārbar, vielleıcht sogar absıchtlich. Plutarch seinerseits hat hıer ohne Zweifel aus Ktesias geschöpft, den er im Artaxerxes durchgāngig benutzt (cf. Heeren de fontib. Plut. p. 94 sqq.), wenn auch mıt Hinzuziehung eınıger anderu Quellen, wie namentlich des Dinon.

Schlıesslich bemerke ıch, dass zwischen Zouaras und Huppolytus Martyr keine Beziehung obwaltet, wie aus einer Vergleichung mit dem Fragmente des Letzteren erhellt, welches in dem Werke: Daniel secundum Septuaginta, Romae 1772 , p. $95-122$ aljgedruckt ist; dagegen mag Hippolytus leicht eine der Grundlagen des 'Theodoret gewesen sein.

Von p. 138 C med. - p. 146 A enthālt die Geschichte der Judith und des Tobias. Kein bestimmles Citat kommt vor. Iosephus theilı darüber gar Nichts mıt; daher kam es auch wahrschemlich, dass es Zonaras früher am passenden Orte vorzutragen vergass. Nun flickt er es, seime Versäumniss bemerkend, aller chronologischen Ordnung zum Trotz, an einer ganz unpassenden Stelle ein und führt den Nebukadnezar noch einmal lebend vor, nachdem er ilın schon, dem Gange des Iosephus gemäss, hatte sterben lassen 
251(p. 122 D). Dic Quellen dieses Anhăngsels sind uatürlich die Bücher Judith und Tobias, und zwar, wie eine Vergleichung lehrt, die alleinigen. Es ist ein wōrtliches Excerpt.

Zneite Hälfle (c. 15-fin. p. 146-169).

Die persische Geschichte bis auf den Tod des Cyrus.

Namentlich werden angeführt: 1) Xenophon p. $146 \mathrm{~B}$ (cf. Cyrop. I. 2, 3); p. 164 D; p. 168 D. 2) Herodot p, 164 B; p. 168 D; p. 169 A. 3) losephus p. $164 \mathrm{D}$. Beı diesem Abschnitte legt Zonaras zum erstenmal den Iosephus auf lăngere Zeit bei Seite. Des Cyrus Geschichte erscheint $\mathrm{hmm} \mathrm{zu}$ interessant, $\mathrm{um}$ sie in seinen universalhıstorisch sein sollenden Annalen ebeuso leicht übergehen zul dürfen, wie Iosephus in einem Werke, das bloss die jüdische Geschichte behandelt. Er will, wie sein sehr unlistorisches Bekenntniss lautet (p. $146 \mathrm{~A}$ ), durch seine Darstellung die Wahrhaftigkeit der Prophezeiungell über den Untergang Assyriens demonstriren. Aber welchem Gewăhrsmanne sollte er folgen? Schon die altesten Schriftsteller wichen über den Eroberer bedeutend von einander ab. Den Ktesias kannte er nicht; den Herodot wollte er nicht, und so fiel seine Wahl auf den romanhaften Xenophon, er ward sein einziger Führer; der ganze Absclnnitt ist nur em Excerpt aus der Cyropådie. Doch hören wir ihn selbst' Am Schlusse der Darstellung sagt er (p. 168 D, 169 A): „Das nun erzăhlt Xeilophon von Cyrus. Aber der Halikarnassier Herodot sagt ūber des Cyrus Erziehung und Tod und über dessen ganzes Leben andere Dinge, welche durchzugehen wohl zu lang wăre. Und mir, der ich ein Compendium der Geschichte verfasse, ziemt es nicht, eine weitschichtige Abhandlung zu geben, sonderu ich habe meinerseits das Glaubwürdigere geschrieben. Wem es jedoch beliebt, auch das zu rernehmen, was vou Herodot über ihn geschrieben ward, der wird, dessen Werk zur Hand nehmend, dasselbe in dem ersten Buche finden, dem er den Namen der ersten der Musen, den der Klio, vorsetzte." Abgesehen von dem 
in den letzten Worten steckenden Jiterarischen Irrthume, bemerken wir, dass er zwar wirklich in den Herodot ein wenıg hineingeblickt, aber dem Xenophon der grösseren Glaubwürdigkeit wegen den Vorzug gegeben habe. Mag sein' Mir will es indessen scheimen, als sei seine Wahl auch eben durch das anzieliende Moment der Xenophontischen Romantik und durch die Scheu vor mühevoller Vergleichung motivirt worden. Genug, er beginut mit dem zweiten Capitel des I. Buches des Xenophon und endigt mit dem siebenten Capitel des VIII. Buches und einer kurzen Inhaltsanzeige des achten und letzten Capitels. Die specielle Controle wird Jeder leicht führen können über diese Cyropädie en miniature.

Die Zusătze sind ganz unbedeutend. P. 148 B sagı er: "Cyaxares, der auch Darius genannt ward. "Das hat er, wie wir oben gesehen, aus Iosephus und Theodoret. Ibid. schaltet er bei der Aufzählung der den Assyrern unterworfenen Völkerschaften die Hebrãer ein, und andere ähnliche Kleinigkeiten. P. $164 \mathrm{~B}$ ist durchaus wörtlich aus Xenophon (l. c. VII. 5, 7-15) über die Belagerung Babylon's; weil derselhe aber den Fluss dieser Stadt nicht benennt,

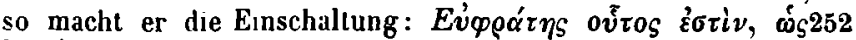
'Hoódoros íropei. Das ist das Einzige, was er aus diesem entnimmt. Um eines Wortes willen kann man aber nicht von Benutzung sprechen; de n Zusatz hätte er ja auch ohne Herodot's Autorităt machen können. P. 164 D setzt er den Namen des Königs - Baltasar, den Xenophon ganz verschweigt, aus Iosephus hinzu, ohne dass er desshalb nŏthig hatte, den Letzteren wieder einzusehell, da er die Materie unter Iosephus Führung schon in dem vorhergehenden Abschnitte behandelt hatte. Er weist selbst darauf zurück (cf. Ios. X. 11, 4. Zon. p, 123).

Wie verhălt es sich schliesslich mit' denjenigen Stellen, wo Zonaras sich das Ansehen eines belesenen, aus vielen Büchern forschenden Gelehrten gibt? z. B. p. 152 B: $\tau \dot{\alpha}$

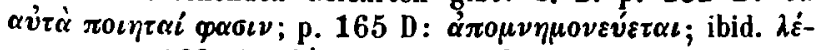

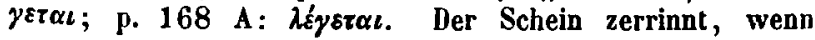
man ihm nahe tritt: es sind nur entlehnte Phrasen und 
Wörter, ebenfalls dem Xenophon (IV. 2, 30. VIII. 2, 14. VIII. 2,15 . VIII. 6,20 ) angehörig.

Die Quellen des vierten Buches (p. 169-215). Vom Tode des Cyrus bis auf Antiochus $\vartheta$ gòs und Simon, den Bruder des Jonathan.

1) Iosephus. 2) Herodot. 3) Plutarch. 4) Arrian. Von p. 269 a med. -D fin. Hier kehrt er zum Iosephus zurūck, olıne ilın zu citiren, und stellt nach ihm (XI. c. 1, 1-c. 3) das Verhältniss des Cyrus und Cambyses zu den Juden dar, und zwar Wort für Wort abschreibend, nur dass er dem Cambyses 7 Jahre beilegt, während Iosephus nur 6. Diese Abweichung erklärt sich daraus, dass Zonaras im Folgenden den Herodot consultirte und ihm also die Stelle unter die Augen fallen musste, wo dieser (III. 66, 2) die Regierungsdauer des Cambyses auf 7 Jahre 5 Monate angibt; danach corrigirte er nun. - Die Magierherrschaft und des Darius Thronbesteigung berührt losephus nur ganz obenhin (lib. I. c. 3, 1); dagegen meint Zonaras (p. 169 D):

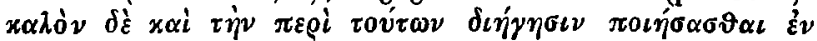

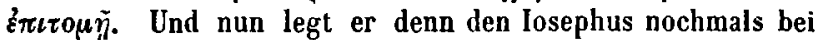
Seite, um von p. $170 \mathrm{~A}-173 \mathrm{~B}$ den Herodot (III. 6468) zu excerpiren. Er fallt hierbei gleich in eine lnconsequenz; denn während er früher, dem Xenophon folgend, den Bruder des Cambyses Tauaoxares genannt, nennt er ihn jetzt fortwährend nach Herodot Smerdes. Dieser plötzliche Widerspruch, in den zu gerathen seine Unwissenheil nicht voraussehen konnte, zwingt ihn jetzt zu einleitenden Worten (p. $170 \mathrm{~A})$ : "Camhyses hatte einen Bruder, welchen Xenophon Tanaoxares, Herodot aber Smerdes nennt." Sonst citirt er den Herodot nicht weiter; das Excerpt ist aber wieder völlig wortgetreu. Wie jämmerlich das Verfahren des Zouras ist, zeigen auch fernere Inconsequenzen: p. 169 D hatte er nach Ioseph. XI. 2, 2 den Cambyses $\dot{\varepsilon} \nu \Delta \alpha \mu \alpha \sigma x \omega$ sterben lassen; jetzt erzăhlt er (p. 170 C D) dessen letzte Augenblicke noch einmal nach Herodot, und lässt ihn mit diesem im syrischen Ekbatana sterben. Doch hiervon geuug. Nur der Schein seiner Gelehrsamkeit muss auch hier 
vernichtel werden; denn die prunkenden Phrasen: oi $\mu \grave{z} \nu$

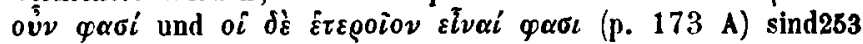
nur aus Herod. lib. I. c. 87 herübergebolt.

Von p. 173 B-p. 183 B med. - Die jūdische Geschichte von Darius Hystaspes bis auf Alexander; wörtlich abgeschrieben aus losephus von dem Punkte an, wo er oben Halt gemacht, d. h. von XI. c. 3-c. 8, 4. Namentlich wird derselbe angeführt p. $176 \mathrm{D}$ (cf. Ios. XI. 5, 2). nie Abweichungen sind unbelentend, wie $z$. B. dass er p. $182 \mathrm{D}$ den Sohn des Joannes Joad nennt, während Iosephus XI. 7, 2 Jaddus oder nach anderen Handschriften Joaddus schreibt.

Von p. 183 B med. - p. 197 B. - Die Geschichte Alexanilers des Grossen. Nach seiner gewöhnlichen Art, die wir nun schon kennen, sagt Zonaras beim Eingange: $z \pi \varepsilon i$

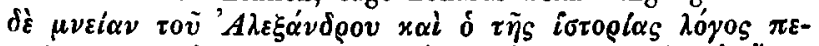

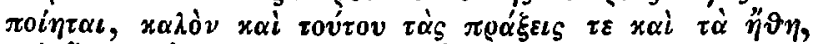

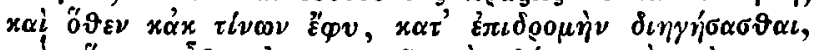

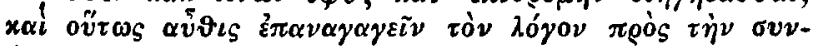

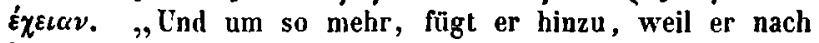
Jerusalem kam u. s. w. " (Mau sieht, wie er selbst die jüdische Geschichte in dem ersten Theile seines Werkes als Mittelpunkt setzte), ,und weil er selbst, wie Iosephus erzählt (hiermit respicirt er auf Jos. XI. 8, 5) ein göttliches Traumgesicht deutete, was wir im weiteren Verlauf der Erzăhlung, nach der Geschichte Alexanders, melden werden." Nun beginnt er das eigentliche Thema mit der Herkunft des Helden, und da ihn Iosephus hier verlässt, so wählt er sich einen neuen Führer, den er jedoch vicht nennt. Es ist aber kein anderer als Plutarch; denn der Anschein vielforschender Gelehrsamkeit ist wieder nur ein Reflex der Plutarchischen Darstellung. Er epitomirt gleichsam die fremde Quellenforschung nicht minder wie die Erzählung der Thatsachen selbst. Man sehe nur zu:

p. $183 \mathrm{C}: \mu v \vartheta \varepsilon v \varepsilon \varepsilon \alpha \iota$ ist aus Plut. Alex. 2. T. IV. ed. Reiske. p. " " $\lambda \dot{\varepsilon} \gamma \varepsilon \tau \alpha \iota \delta \dot{\varepsilon}, ", "$, ,. 3.

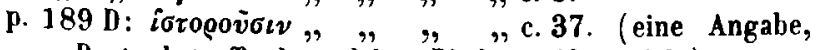
Beute betreffend, welcher "Diodor widerspricht). 
p. $194 \mathrm{C}$ : $\lambda \dot{\gamma} \varepsilon \tau \alpha \iota$ ist aus Plut. Alex. c. 66 .

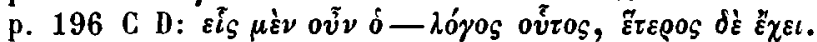

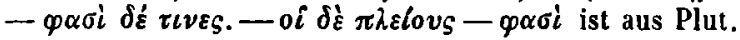
Alex. c. 75.76 .77 .

Eine vollstãndige Vergleichung wăre überflüssig. Genug, wir haben im Zonaras einen kleinen Plutarch; nur dass er zuweilen dıe Reihenfolge desselben åndert. Z. B. p. $188 \mathrm{C}$, enthaltend den Ausspruch der Olympias, den Plutarch schon c. 3 mittheilt. - Abweichungen sind sonst nicht vorhanden, denn dahin dürfen wir es schwerlich rechnen, wenn er p. 193 B die Breite des Ganges zu 62 Stadien berechnet, wăhrend Plutarch c. 62 nur von 32 spricht. Da er durchaus keinen Autor weiter vor Augen hat und dem Plutarch hier Wort für 'Wort folgt, so beruht die Verschiedeuheit sicher auf einem Schreibfehler oder auf einer Corruption, sei es, dass diese in dem von ihm benutzten Manuscrıpt des Plutarch vorhanden war, oder dass sie einem späteren Abschreiber beizumessen ist. Die Angabe, womit

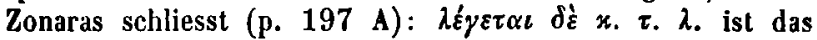
einzige Nicht-Plutarchische im ganzen Alsschnitt; die Stelle stimmt grossentheils wörtlich nit Arrian VII. 27 ; vielleicht 254ist es eine Reminiscenz oder fliesst aus einer in dem von Ihm gebrauchten Codex des Plutarch gefundenen Randbemerkung eines glossirenden Lesers, denn wir dürfen nun einmal dem Zonáras nicht viel zutrauen; dass er aber gar um dieser einzigen Bemerkung willen eine besondere Quelle zur Hand genommeu, wird man noch weniger glauben. Den Schluss des Plutarch c. 77 fanden wir schon frūher (p. 127 A) mitgetheilt; wahrscheinlich hat Zonaras erst jetzt diese Stelle dort nachgetragen.

Von p. $197 \mathrm{~B}-$ p. 215, oder bis zum Ende des vier. ten Buches. - Vou den Verhăltnissen Alexanders zu den Juden bis auf des Antiochus $\vartheta \varepsilon \dot{s}$ S Tod durch Tryphon.

Nach seinem Besuche bei Plutarch berupft hier Zonaras von Neuem den Iosephus (cf. XI. 8, 4-XIII. 7), den er auch einmal, bei Gelegenheit der Septuaginta, nennt (p. $200 \mathrm{C}$. cf. Ios. XII. 2, 12). Die verscbiedenen Ansicbten hierüber mussteu dem Möncbe geläufig sein, und so kann es uns 
nicht wundern, wenn er nach dem Berichte des losephus noch einen anders lautenden hinzufügt, nämlich den genugsam besprochenen des Epiphanius, der im vierten Jahrhundert schrieb, wonach je 2 und 2 von den 72 Interpreten in abgeschlossenell Gemächern die Uebersetzung zu Stande gebracht. Er neunt jedoch den Epiphanius nicht, sondern sagt ganz allgemein: $\varepsilon_{\varepsilon} \tau \rho o \iota ~ \delta_{\varepsilon}^{\prime}-\varphi \alpha \sigma \iota$. Natürlich bedurfte er, um dergleichen zu melden, keiner bestimmten Quelle; es sind Zusătze aus der Totalităt seines Wissens. - Dass Zon. in diesem Abschnitte auch die h. Schrift, und namentlich die Bücher der Makkabãer benutzt, mōchte ich bezweifeln; seine Nachrichten gehen alle und meist wörtlich in die des losephus auf.

Die Quellen des fünften Buches (p. 215-260).

Von dem Tode des Antiochus fés bis auf den Tod des Herodes.

Das Ganze ist aus Iosephus XIII. 7-XVIl. 8, 4. Er

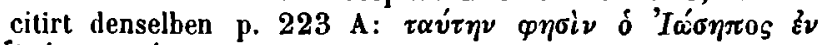

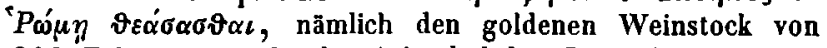
800 Talenten Werth, den Aristobul dem Pompejus schenkte. Zonaras hegeht aber wieder eine grosse Nachlässigkeit, denn Iosephus (XIV. 3, 1) sagt das nicht von sich selbst, sondern es sind die direct angeführten Worte des Strabo. Ferner citirt er ihn p. 241 D (cf. Ios. XV. 9, 2). Auch da, wo er unbestimmte citatorische Ausdrücke gebraucht, steckt losephus dahinter, z. B. p. $217 \mathrm{C}: \lambda \dot{\varepsilon} \gamma \varepsilon \tau \alpha \iota$ x. $\tau$. $\lambda$.

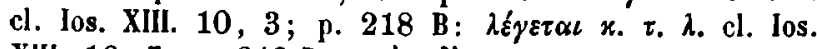

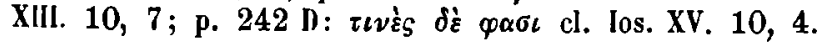

Die Quellen des sechsten Buches (p. 260-313). Yom Tode dcs Herodes bis zur Zerstörung von Jerusalem.

P. $260 \mathrm{C}-$ p. $291 \mathrm{~B}$ ist entlehnt aus loseph. Autiqq. XVII. 8, 4-XX fin. Namentlich angeführt finden wir ihn p. 267, wo Zonaras das Zeugniss desselben (XVIII. 3, 3) über Jesus Christus, mit der Angabe des Buches der Antiquitäten, beibringt. Für unsern Zweck ist die Entscheidung 
der Frage, ob jenes Zeugniss echt oder untergeschoben, von keinem Einfluss; dass es jedoch mindestens schon im vierten Jahrhundert in den Manuscripten des losephus ge255lesen wurde, ist aus der Anführung des Eusebius (Hist. eccl. I. c. 11) klar. Bei dieser Gelegenheit macht aber Zon. noch einige Zusătze. Die Merkwürdigkeit der Sache brachte es mit sich, dass sie allgemein in der Christenheit besprochen wurde; auch Zon. musste daher Manches darüber vernommen und gelesen haben. Nunmehr beschränkt er sich nicht auf die blosse Mitlheilung jenes Zeugnısses, auf dessen Wichtigkeit er schon in der Einleitung (p. 9 A) aufmerksam gemacht hatte, sondern führt p. 267 D und p. 268 A B ein noch ausführlicheres desselben Autors an, und zwar aus dessen Rede an die Hellenen, deren, wie er hinzufügt, auch der $\mathrm{h}$. Iohannes Damascenus in seinen $\mathrm{Pa}$ rallelen gedenke. Dieser Schriftsteller des achten Jahrhunderts, einer der Regrūnder der systematischen Theologie und, wie seine $x \varepsilon \varphi \alpha \dot{\lambda} \alpha \iota \alpha$ $\varphi \iota \lambda 0 \sigma o \varphi \iota x \alpha \dot{\alpha}$ beweisen, mit den phılosophischen Systemen ziemlich vertraut, nahm jederzeit die allgemeine Aufmerksamkeit des theologischen Publikums in Anspruch. Auch Zon. beschäftigte sich mit ihm und schrieb, wie wir aus der Angabe seiner Werke ersehen

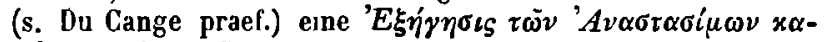

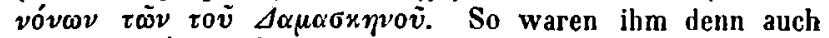

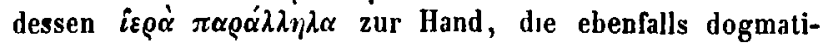
schen Inhalts sind. Leıcht kōnnte desshalb der Verdacht

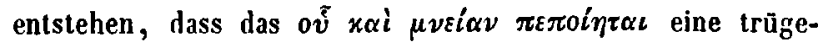
rische Wendung und das Ganze nur ein Plagiat 'aus dem Damascenus seı. Diess erweist sich jedoch als ungegründet; denn die Stelle, welche Zon, aus jenem philosophischen גóyos recilirt, findet sich zwar bei loann. Dam. Opp. omn. ed. Par. T. Il. p. 755, wird aher von demselben dem Bischof Meletius vindicirt (

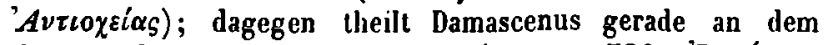
Orte, welchen Zon. im Simu hat (1. c. p. 789: 'I $\omega \sigma \eta \dot{\eta} \pi 0 v$,

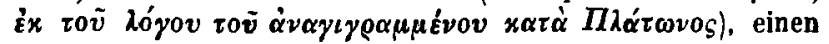
ganz anderen Abschnitt der betreffenden Schrift mit. Das bedeutendere Fragment derselben, welches Höschel aus Ita- 
lien erhalten und in seiner Ausgabe des Photius (p. 923) zuerst abgedruckt hat (es steht auch im Ios. ed. Haverkamp. T. Il. p. 146), beginnt mit dem Inhalt des Bruchstũckes bei Ioann. Dam. p. 789 , dann folgt ein soust unbekannter Theil, hıerauf der Inhalt des Bruchstǔckes bei Zon. 1. c. und bei Ioann. Dam. p. 755, und endlich wieder ein unbenutztes Stück als Schluss. Nun ergibt die Vergleichung, dass die Worte des Zon. vollkommen mit dem Orıginaltexte übereinstimmen, die des Damascenus aber fast durchgãngig modificirt sind; mithin ist Zon. augenscheinlich auf das Original selbst zurückgegangen und hat von dem angeblich Josephischen Antiplatonismus eine unmittelbare Kunde gehabt; denn mit Recht gilt die Schrift $\pi \varepsilon \rho i$

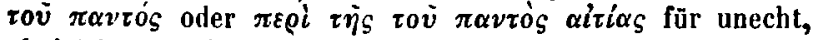
obgleich die Herausgeher des Fragments den Namen des losephus nicht getilgt, und due des Letzteren die Aufnahme nicht versagt haben (vergl. u. A. Hoeschel. ad Phot. l. c.; Th. Ittig. Prolegom. ad loseph. v. fin.; adn. ad Ioann. Dam. l. c. p. 7891. Daher war sie auch sicher den Exemplaren des Iosephus nicht angehäugt, so dass Zon. sie sıch anderweitig verschaff haben muss; denn einmal hätte dann auch Eusebrus sich gewiss dieses zweiten Zeugnisses bedient, und andererseits würde sie dann auch in den heutigen Codices256 sıch finden. Dem Damascenus mag übrigens die Tăuschung verziehen werden; da aber bald nach ihm, schon im neunten Jahrhundert, die Abhandlung durch Photıus (bibl. cod. 48) für untergeschoben erklärt wurde, so ist es wieder ein Beweis von Unwissenheit, wenn Zon. dessenungeachtet nicht den geringsten Zweifel dagegen hegt. Und doch war Photius so berühmt. Zon. selbst kennt und nennt ihn als historische Individualität (L. XVI. T. II. p. 161 D sq.). Uebrigens scheint in Betreff jenes literarischen Findlings die Stelle des Zon. bisher meist unbeachtet geblieben zu sein.

Ferner wird losephus citirt p. 271 A über Ioannes den Täufer (cf. praef. p. 9 A los. XVIII. 5, 2) und p. 290 B

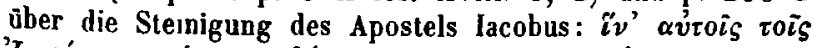

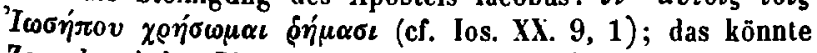
Zon. bes jeder Phrase sagen; auch da gilt es, wo er mit 
anscheinendem Selbstwissen auftritt, wse p. $271 \mathrm{D}$; $\lambda \varepsilon \dot{\gamma} \varepsilon$ $\tau \alpha \iota$, aus Ios. XVIII. 5, 3. p. $287 \mathrm{C}: \lambda \varepsilon \varepsilon \varepsilon \varepsilon \alpha \iota$, aus los. XX. $7,2$.

Ich erwähne noch einer Abweichung. Zon. berührt im sechsten Buche durchgehends die Kaisergeschichte, aber nur aus dem Gesichtspunkte der jüdischen Geschıchte, so dass auch hierin losephus $\mathrm{hm}$ genügt. In den folgenden behandelt er sie eigens und ausführlich nach Dio Cassius. Da geschieht es denn, dass er einige Verbesserungen aus dem Dio in sein Excerpt aus dem losephus stillschweigend hineinträgt. So gibt er z. B. p. 275 B die Regierungsdauer des Tiberius nicht nach dem Letzteren (XVIII. 6, 10), aus dem er doch alle übrigen Worte entlehnt, auf 22 Jahre 5 Monate 3 Tage, sondern nach dem Ersteren (Lib. 58 fin.) auf 22 Jahre 7 Monate 7 Tage an. Nur so ist diese $\mathrm{Ab}$ weichung zu erklăren; denn dürfte man auch aus dem Grunde an eine Corruption im Iosephus denkell, weil dieser Im zweiten Buche de bello lud. c. 8 sechs Monate angibt (cr. Relaud. ad Antıqq. l. c.), so darf man doch sicher nicht die Angabe des Zon. hineincorrigiren wollen. Uebrigens ist wohl zu beachten, dass der jüdlische Krieg vor den Antiqq. geschrieben wurde und Iosephus inzwischell anderer Meinung geworden sein konnte. Man ersieht, welche ausserordentliche Behutsamkeit es erfordert, bei Autoren, die in einem Verhältnisse stehen, wie Zon. und Ios., den Text des Einen durch den des Anderen zu constatiren. Wie sehr würde man fehlen, wollte man hier, gleichviel, ob den losephus nach dem Zonaras, oder Diesen nach Jenem ăndern, wie verfäuglıch auch der Schein sein mag; oder wollte man, um ein anderes Beispiel zu nehmen, jene oben be-

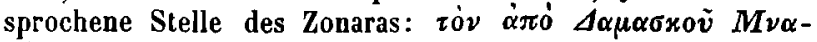
$\sigma \dot{\varepsilon} \alpha \nu$ nach Iosephus corrigiren; denn die philologische Kritik hat nur danach zu forschen, wie der Autor schrıeb, nicht, wie er hätte schreiben sollen.

256 Iosephus hat bekanntlich den Inhalt der Antiquitäteu von XII. 5 an bis zu Ende früher schon in seinem Werke de bell. Iul. summarisch als Einleitung behandelt, von Lib. I. 1-II. 14. Ich bemerke nun als durchaus bestimmt, dass 
Zonaras nicht etwa diese Einleitung, sondern eben jene Bücher der Antiquităten gehörigen 0rtes excerpirt hat; eiue genaue Vergleichung beweist es. Erst mit dem folgenden Abschnitte legt er die Antiquităten bei Seite und nimmt zum erstenmal den jüdischen Krieg zur Hand.

Von p. 291 B - p. 312. Der jüdische Krieg vom zwölften Jahre des Ncro bis zur Zerstörung Jerusalems, nebst einem Anhange.

Es ist ein sehr kurzes, aber meist wörtliches Excerpt aus loseph. de bell. lud. bis zu Ende des Werkes; Zonaras citirt diesen jedoch nicht. Dagegen ertappen wir ihn wieder, wie er Zeugnisse aus Iosephus herüberschmuggelt. Z. B.

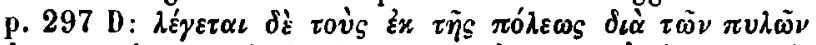

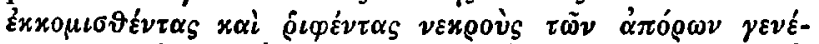

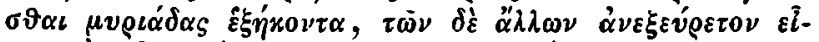

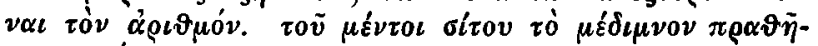
$v \alpha \iota \tau \alpha \lambda \alpha{ }^{\prime} \nu \tau o v$. Woher diese Kunde, erfahren wir aus Ios.

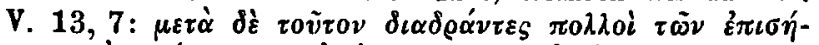

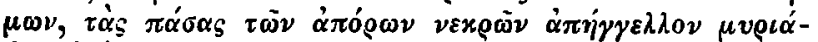

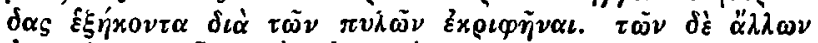

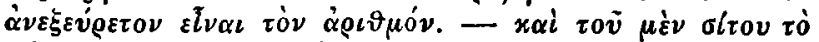
$\mu \dot{\varepsilon} \tau \rho \circ \nu \pi \rho \alpha \vartheta \bar{\eta} \nu \alpha \iota \tau \alpha \lambda \alpha^{\prime} \nu \tau 0 v$.

Die Abweichungen sind unbedeutend und leicht erklärlich. Wenn z. B. Zonar. p. 291 C sagt: „Vespasian habe die Stadt Jotapata belagert $\dot{\pi} \pi i$ $\tau \varepsilon \sigma \sigma \alpha \rho \alpha x o \nu \tau \alpha \eta_{\mu \varepsilon} \rho \alpha \varsigma^{\prime 6}$, so geschieht diess nur der runden Zahl wegen. Nach los. III. 7, 33 dauerte die Belagerung über 47 Tage (cf. III. 8, 9).

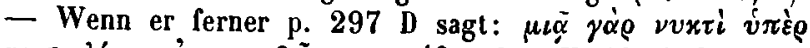

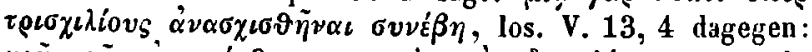

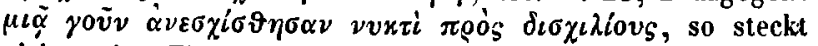
sicher eine Flüchtigkeit oder eine Corruption dahinter.

Noch ist vom Anhang zu reden. Nachdem nãmlich $Z_{0}$ naras p. $312 \mathrm{C}$ mit einem Excerpt aus dem letzten Capitel des letzten Buches (VIl. 11) die Geschichte des Krieges absolvirt, erwāhnt er in einem Zusalze von wenigen Zeilen258 des jüdischen Aufstandes unter Aelius Adrianus, mit der

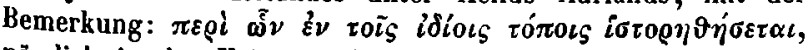
nänlich in der Kaisergeschichte Lib, XI. p. 589 D sq. Wir 
werden spăter von den Quellen dieses Buches sprechen; erst nach der Ausarbeitung desselben hat er wohl den hier in Rede stehenden Zusatz eingeschoben. - Endlich folgt p. $312 \mathrm{C} \mathrm{V}$ ein kurzer Uebergang zum siebenten Buche. Er

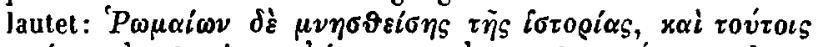

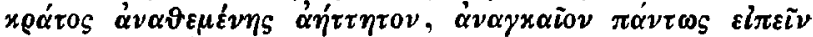

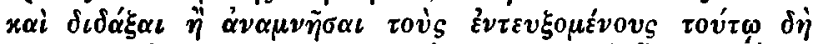

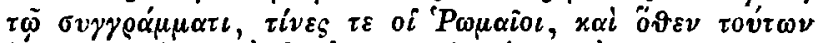

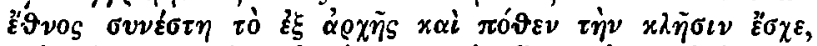

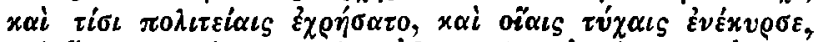

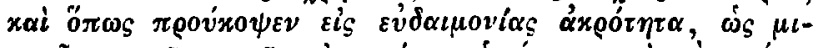

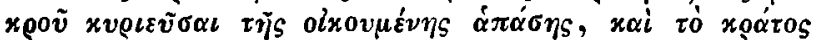

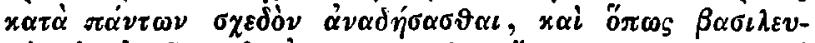

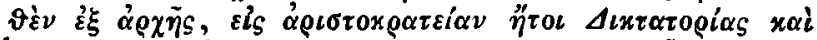

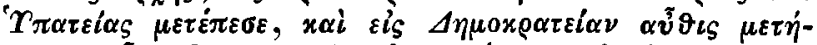

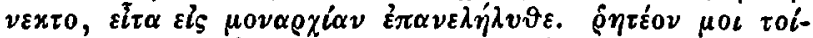

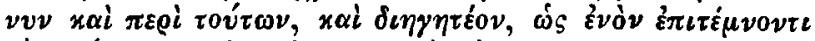

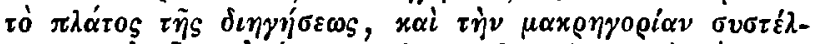

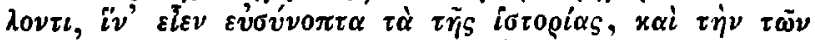

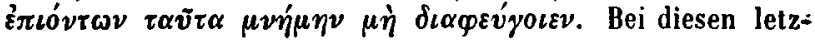
teren Aeusserungen hat Zouaras das rãsonnirende und rhetorisch-declamatorische Element der Quellen im Sinu, die er zu excerpiren sicb anschickt, und welches er auch schon in der Einleitung getadelt und zu vermeiden versprochen hatte.

Die Quellen des siebenten, achten und neunten Buches (p. $213-471$ fin.).

Die römische Geschichte ron Aeneas bis auf die Zerstörung Karthagos und Korinths.

Zonaras nenut nur ein einziges Mal seine Quelle (denn der beiläufig citirte Herodot p. $330 \mathrm{D}$ ist nicht zu rechnen), nämlich den Plutarch p. 459 B. Sonst gebraucht er nur Ausdrücke, wie p. 314 C: $\tau \iota \nu \varepsilon \dot{s}$ ó $\delta^{\prime} \alpha \sigma \iota ;$ p. $316 \mathrm{~A}$ :

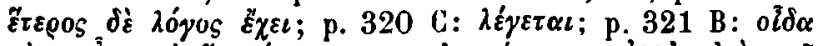

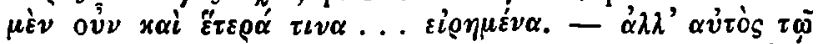

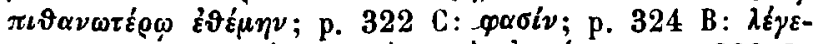

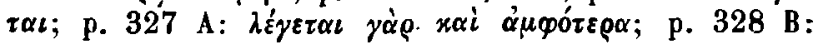




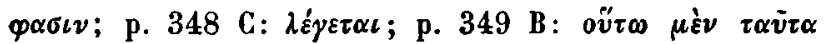

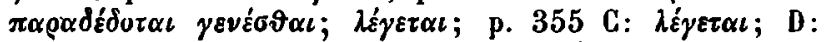

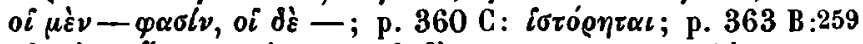

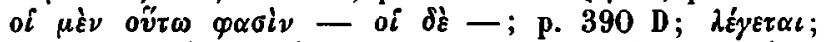

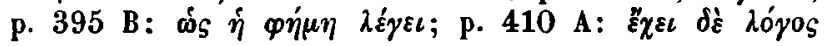
u. s. w.

Dass Zonaras in diesem grossen Abschuitte vi ele Quellen benutzt, wie Reimarus ad Dion. praef. \$. 13 meint, daran ist gar nicht zu denken; das wäre eiuem Zunaras eine viel zu complicirte Sache gewesen; er geht einfach und gerade und überlâsst die gewundenen und saueren Wege

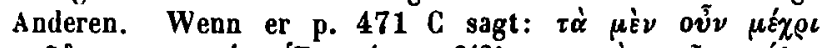

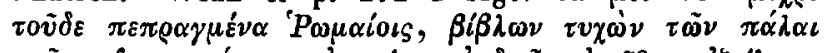

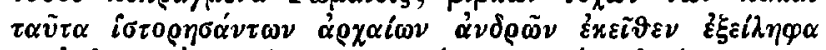

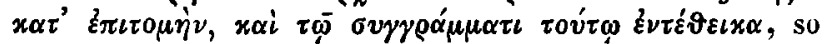
sehe ich nicht ein, warum diess, wie Reimarus will, für die Benutzung vieler Autoren sprechen soll; es passt vollkommen, auch wenn Zonaras nur $z w$ e $i$ benulzt. Und in der That, die Quellen, aus denen allein er den ganzen vorliegenden Abschnitt entnommen, sind nur zwei: Dio Cassius und Plutarch.

Namentlich ist nicht an eine Benutzung des Polybius und Appian zu denken; denn obgleich Zonaras sie citirt, woraus eben Reimarus seine Vermuthung schōpfte, so sind diess einerseits, wie wir an den gehörigen Orten nachgewiesen oder nachweisen werden, Scheincitate, und andererseits nennt er dieselben auch nicht einmal in unserem Abschnitte, wodurclı allenfalls die Vermuthung hătte ein grōsseres Gewicht bekommen können. Ueberdiess spricht noch ein allgemeiner Grund, den wir unten in Betracht ziehen werden, durchaus für die Nichtbenulzung des Appian. Wenn aber Reimarus glaubt, durch die Worte p. 6: $\dot{\varepsilon} x$

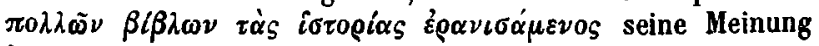
bekrãftigen zu können, so weiss ich vollends kaum, was ich dazu sagen soll. Spricht demn Zonaras an dieser Stelle nicht ganz klar und deutlich von seinem gesammten Werke? Keineswegs bloss vou dem in Rede stehenden Abschnitt. llas $\pi \cap \lambda \lambda_{0} \nu$ darf nicht aus seiner Beziehung herausgerissen 
und dann willkürlich gefulgert werden. An jener Stelle ist es allerdings begrüudet, denn Im Ganzen mag Zonaras doch ein Dutzend Bücher gebraucht haben, was einem Literaten seines Gelichters schon viel däuchte; p. 471 aber, wo er nur von unserem Abschnitte redet, hat er sich wohl gehütet, einell solchen Ausdruck zu gebrauchen, und sagt nur ganz unbestimmt und vorsichtig: $\beta i \beta \lambda \omega \nu \tau v \chi \omega ́ v$. Um diess aber sagen zu dürfen, braucht er, diess sieht Jeder ein, nur zwei Werke benutzt zu haben, zumal da der Ausdruck auch die einzelnen Abthellungen eines und desselben Werkes bezeichnen kann. Ich darf es dreist aussprechen, ohne die unermesslichen Verdienste Reimar's schmalern zu wollen, dass derselbe diesen Punkt sicher nicht mit voller Einsicht behandelt hat; ja, ich thue es nothgedrungen, damit der zrosse Name des Behauptenden nicht einer irrthümlichen Behauptung Vorschub leiste.

Wir wollen nun die Untersuchung an die beiden genannten Quellen, Dio und Plutarch, anknüpfen.

I. Dio. $\mathrm{Da}$ diejenigen seiner Bücher, welche mit den vorliegenden des Zonaras gleichen Inhalts waren, verloren sind, und der Letztere ihn nicht ein einzigmal citirt: so kōnnte die Sache bedenklich scheinen. Allein ein indirectes 260Verfahren hilft aus, nămlich die Vergleichung mit den hier und dort erhalteneu Ueberresten des Dio. Das Resultat, welches wir vorannehmeu, ist: Bei weitem die meisten Fragmente finden sich im Zonaras wörtlich wieder und gehen gleichsam in ihn auf. Es mag genügen, eınige Beispiele auszuführen und auf de übrigen zu verweisen.

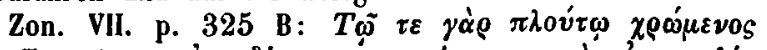

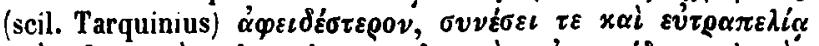

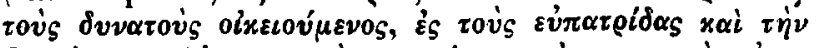

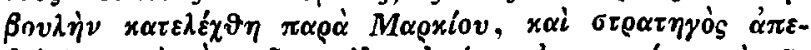

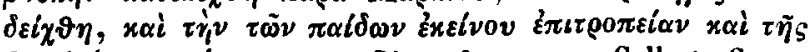
$\beta \alpha \sigma i \lambda \varepsilon i \alpha$ S $\pi \varepsilon \pi i \sigma \tau \varepsilon v \tau o .=$ Dion. fragm. ex Collect. Const. Porphyr. in Excerpt. Peiresc. p. 570, fr. 22 ap. Reim. ôt

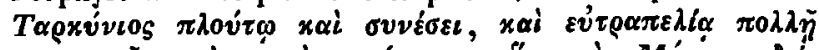

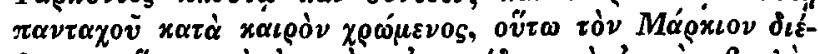

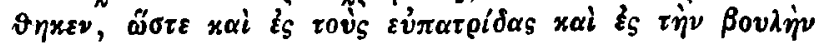




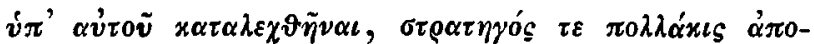

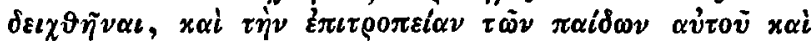

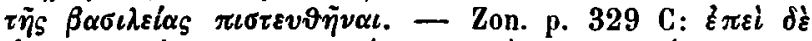

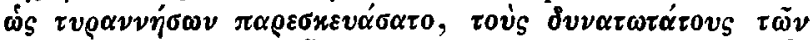

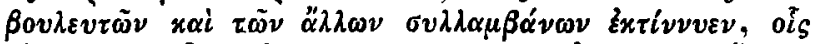

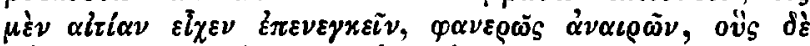

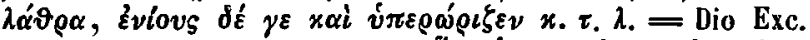

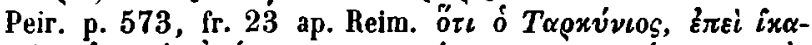

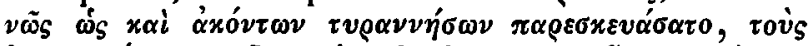

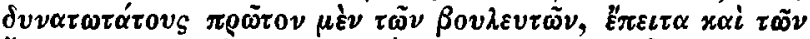

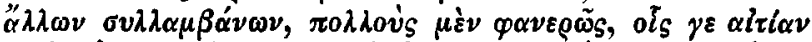

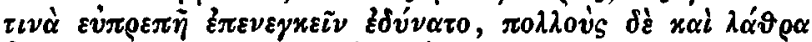

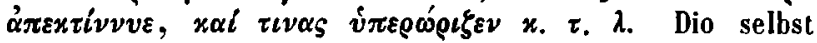
schöpfte aus Livius I. 49 und Dionysius Hal. IV. 42.

Damit jeder Forscher sich überzeuge, dass ich nicht aus einigen Uebereinstimmungen urtheile, lühre ich noch folgende Stellen zur Vergleichung an:

Zon. VII. p. 332 D-333 B = Dio Peir. p. 576 Pr. 24 ap, Reim.

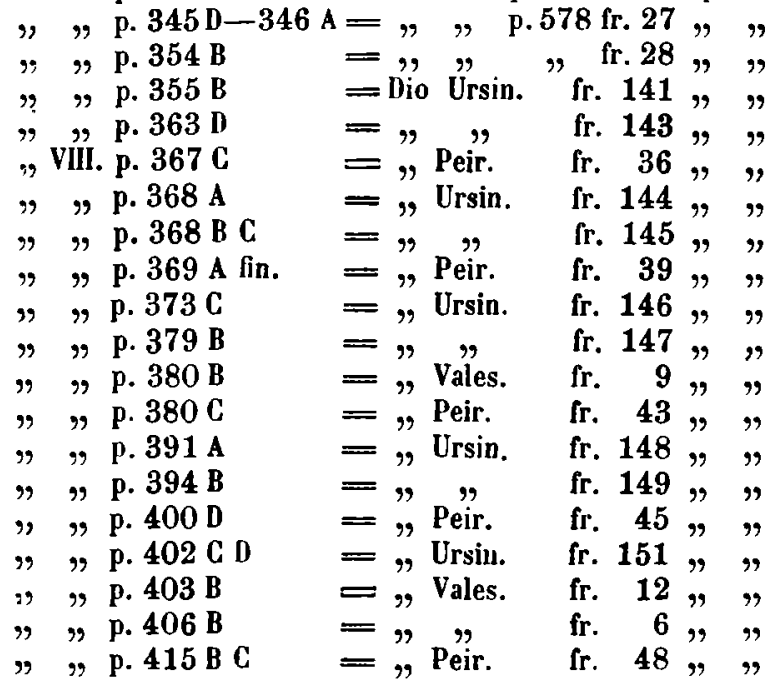


XXVIII Ueber die Quellen des Zonaras.

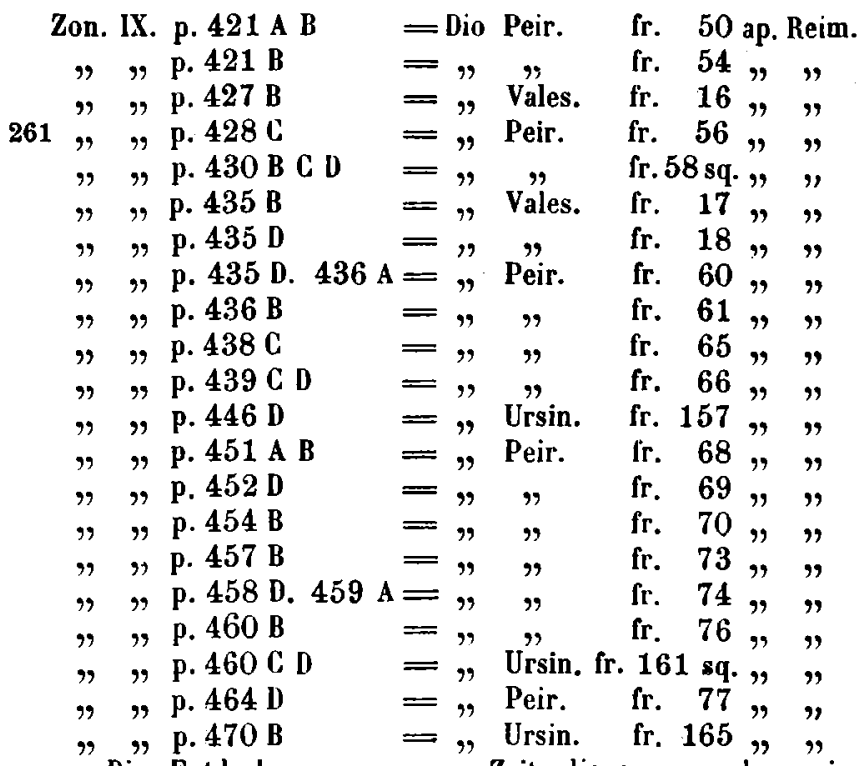

Die Entdeckungen neuerer Zeit dienen nur dazu, im Zon. immer mehr den Dio zu enthüllen und, wo bisher nur Vermuthung, wenn auch zuversichtliche, statthaben konnte, die vollkommeuste Gewissheit zu schaffen; man vergleiche nur Mai's Nov. Coll. II. p. 139-196 mit Zon. p. 324$817 \mathrm{C}$ fin. Fast jede Seite liefert schlagende Beweise, welche der gelehrte Italiener nicht unbeachtet lässt. Z. B. p. 139 VI cl. Zon. 324 C; p. 143 sq. XII cl. Zon. p. 339 B C; p. 144 sq. Xill cl. Zon. p, $339 \mathrm{C}-340 \mathrm{C}$ med.; p. 146 XIV cl. Zon. p. 340 C. 341 D; p. 147 XV cl. Zon. p. 342 D; p. 148 XVI cl. Zon. p. 343 C med.; p. 148 sqq. XVII. XVIII cl. Zon. p. 343 C med. -344 B; p. 150 XVIIII cl. Zon. p. 344 B; p. 155 XXVII cl. Zou. p. $359 \mathrm{C}$; p. 165 XL cl. Zon. p. 366 A; p. 168 XLIIII cl. Zon. p. 368 B; p. 171 sq. XLVIII sq. cl. Zon. p. 372 A C D und so fort. In der Sammlung des Planudes und dem florileg. vatican. s. besonders ebendaselbst p. 528, 531, 533 
cl. Zon. p. $360 \mathrm{D}-361 \mathrm{~B}$. So sehen wir die Intervallen in unserer obigen Vergleichung mit den in den Ausgaben des Dio vorhandenen Fragmenten sich nach und nach füllen.

Hierzu kommt nun aber noch: Wenn man den Zonaras in diesen Abschnitten mit Ljvius und Dionysius von Halikarnass vergleicht, so findet man eine ungemeine und fast durchrehende Aehnlichkeit in den Angaben, minder in den Worten. Die Sache steht augenscheinlich so: Dio wählte in den ersten Theilen seiner Geschichte jene beiden Historiker zu seinen vornehmsten Gewährsmännern*), schmolz aber deren Worte um und setzte aus Beiden zusammen, wie man aus der zweiten oben ausführlich gegebenen Stelle ersehen kann; Zonaras andrerseits schrieb nun den Dio aus; daher kommt es, dass er mit den Fragmenten desselben wörtlich übereinstimmt, wo diese uns aber verlassen, wenigstens häufig mit den thatsăchlichen Angaben jener beiden Autoren. Auf diese Weise werden die Aehnlichkeiten mit ihnen ein neuer Beweis, dass Zonaras bei weitem mehr262 noch den Dio benutzte, als wir durch blosse Confrontation darzuthun im Stande sind. Ganz so wie in jener zweiten mitgetheilten Stelle (p. 329 B C) zeigt Zonaras öfters eine Verschmelzung der Angaben des Livius und Dionysius, und wie jene sich als dem Dlo angehörig ergab, so werden wir auch alle ähnliche als sein Eigenthum erkennen müssen. An ein Zurückgehen des Zonaras selbst auf jene beiden Schriftsteller ist dabei nie zu denken. So ist nun auch sicher das Citat des Herodot über den Milesischen Thrasybul bei Gelegenheit der Verfahrungsweise des Sextus Tarquinius gegen Gabii (p. 330 D) aus Dio entlehnt. Livius I. 54 macht jene Vergleichung mit Thrasybul gar nicht, und bei Dionysius IV. 56 ist sie zwar vorhanden, aber Herodot nicht genannt. Dio, eben aus Beiden schöpfend, setzte gewiss auch die Quelle hinzu, aus der Dionysius die pa-

*) Einen Beitrag zu der Beweisfithrung, dass Dio den Diongsius benutzt, gibt unter anderen neueren Entdeckungen das Fragment IV des Dio in Bekker's Anecd. I, p. 133, 8 cl. Dionys, V, 34. S. Niebuhr R. G. I. p. 610 n. 1219.

ZONARAS VI. 
rallele Thatsache entnahm. *) Zudem hat Zonaras augenscheinlich keinen römischen Schriftsteller benutzt; einerseits citirt er keinen einzigen, und dann führt uns auch die Untersuchung selbst da jederzeit auf griechische Quellen, wo er römische hătte zu Rathe ziehen können und müssen, wofern er irgend auf Bedeutung Anspruch machen wollte; so in der Kaisergeschichte. Ueberhaupt lasst es sich mit Grund voraussetzen, dass er das Lateinische gar nicht verstanden. Auch den Dionysius citirt er nirgends, während er den Dio sonst gar häufig, nur nicht in diesen Abschnitten, erwăhnt. Ueberdiess ergibt sich die Nichtbenutzung des Ersteren aus solchen Stellen, wo derselbe mit Dio gerade jin Widerspruch steht und Zonaras dennoch des Letzren Angabe und Worte hat. Dionysius sagt z, B. IV. 42 von Tarquinius: ,Nachdem er den besten Theil des Senates durch Hinrichtung oder ewiges Exil bei Seite geschafft, schuf er selbst einen anderen Senat und setzte seine Freunde in die Würde der Ausgetretenen ein." Dio dagegen, die Angabe des Livius I. 49: Patrum praecipue numero imminuto, statuit nullos in Patres legere vorziehend, sagt (fr.

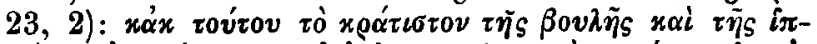

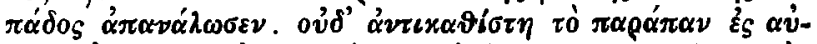

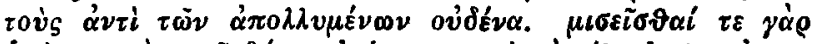

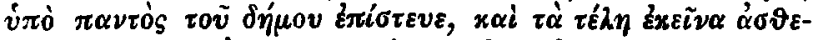

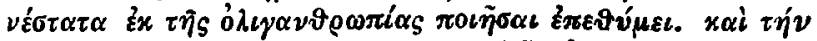

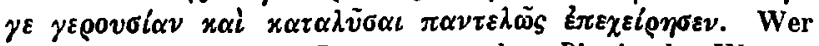
erkennt nun nicht ein Excerpt aus dem Dio in den Worten

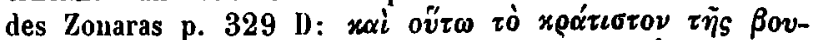

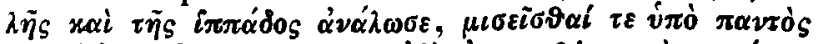

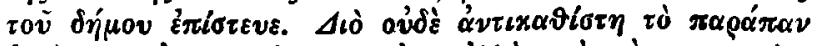

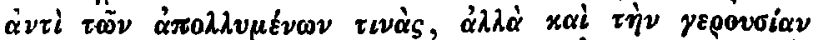

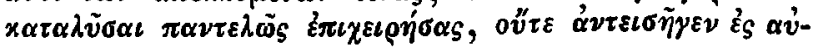

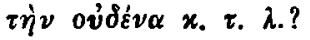

II. Plutarch - als zweite Quelle des siebenten, achten und neunten Buches. Zonaras citirt ihn einmal, IX p. 459 B:

*) Dass die römische Anekdote aus der griechischen entsprang, ist längst erkannt; s. Niebuhr I, p. 290 ed. 3. 


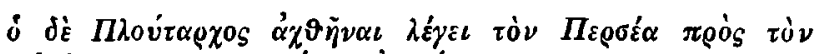

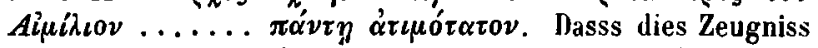
direct aus Plutarch (Aemil. c. 26 ed. Reiske T. II) entlehnt ist, wird durch die Wortüberenstimmung bewiesen; wäre263 es aus Dio gestohlen, so würde die Diclion viel freier sein. Gebraucht hat derselbe sicher den Plutarch, allein eben eln furax und plagiarius war er nicht, und die Plutarchischen Lappen verwerfe ich mıt Reimar (ad Dion. praef. \$. 1214) als eln Flickwerk der librarii.

Aber wie gebraucht Zonaras den Plutarch? - Seine Grundlage ist offenbar Dio; nach ihm bearbeitet er den Zug der Ereignisse; sowie er aber zu der Wirksamkeıt einer berühmten Individualıtät gelangt, deren Lebensbeschreibung im Plutarch enthalten ist, so benutzt er dieselbe, woferu sie sich in semen Hånden befindet, um die Dionischen Umrisse zu füllen. Auf dieselbe Bemerkung ward Valesius geführt (ad Exc. Peir. p. 578 ed. Reın. fr. 28): Solet Zonaras, ubi in aliquam historiam incurrit, quae a Plutarcho refertur, relicto Dione, Plutarchi scrinia complare. Plutarch dient $\mathrm{hm}$ gleichsam zur Ausstopfung.

\section{Näliere Beleuchtung.}

Gleich den Romulus finde ich stark benutzt; denn dass an keine unmittelbare Entlehnung aus Dio zu denken ist, versteht sich von selbst, da sich nirgends in den Ueberbleibseln seines Werkes der Charakter einer so jämmerlichen Abschreiberei kund gibt. Gleıch die Erzāhlung des Zonaras

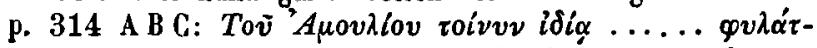

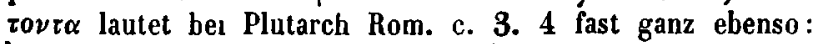

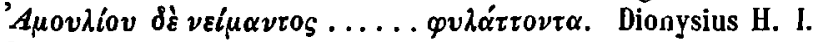
76 sqq. erzählt die Sache zum Theil anders, mit anderen Worten und bei weitem detaillirter - Fährt man nun von dem angegebenen Punkte mit der Vergleichung fort, so stösst man sehr hăufig auf Plutarchisches Eigenthum, wobei

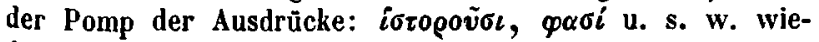
der un Nichts zerfällt. Die Benutzung des Romulus zieht sich durch von p. 314 bis 320 D. lch mache nur noch auf einige Uebereinstimmungen aufmerksam: 


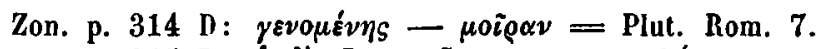

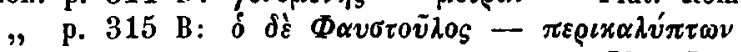

" p. $316 \mathrm{G}: x \tau \iota \sigma \vartheta \varepsilon i \sigma \eta \mathrm{S}-\omega \dot{\nu} \operatorname{có}_{\alpha \sigma \varepsilon \nu}$ $=$ Plut. Rom. 8 .

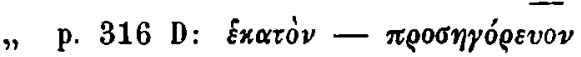
$=$ Plut. Rom. 13. $=$ Plut. Rom. 13.

, p. 320 A: oi $\mu \dot{\varepsilon} \nu$ oṽv $\pi 0 \lambda \lambda \circ i-\vartheta \varepsilon 0 x \lambda v \tau \varepsilon \tilde{\nu}$

(Z.: $i \pi \pi \varepsilon ́ \omega \nu . ~ P l .: ~ \pi \alpha \tau \rho \iota x i \omega \nu)$ $=$ Plut. Rom. 27 sq.

, p. $320 \mathrm{C}: \tau \alpha v^{\prime} \tau \eta \nu \delta \dot{\varepsilon} \tau \dot{\eta} \nu \dot{\varepsilon} \pi \omega \nu v \mu i \alpha \nu \nu \alpha \sigma i-K v-$ @ivov . . . . . . = Plut. Rom. 29 , ibid. $\lambda \hat{\varepsilon} \gamma \varepsilon \tau \alpha \iota-\alpha \dot{\alpha} \varphi \alpha \nu \iota \sigma \vartheta \tilde{\eta} \nu \alpha \iota \rightleftharpoons$ Plut. Rom. 29 extr. Den Numa benutzt er von p. 320 - p. 323 B. s. z. B.

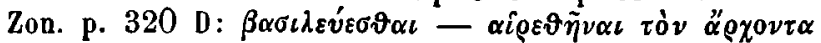
, p. 321

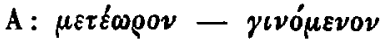
$=$ Plut. Num. 2. $=$ Plut. Num. 2 fin. (Dionysius II. 57 erzăhlt die Sache anders, und wieder anders Livius I. 17. Beider Angaben nahm sicher Dio auf, den Zonaras, wenn gleich dem Plutarch nachstellend, doch fortwăhrend zur Hand hatte; desshalb fügt er, nachdem er auch hier einzig und allein den Plutarch ausgeschrieben, die Worte hinzu: oĩ $\delta \alpha \mu \frac{1}{2} \nu$

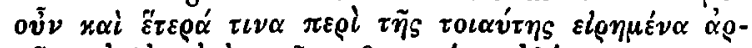

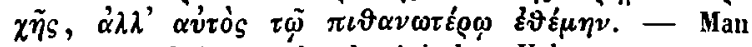
hüte sich übrigens, der lateinischen Uebersetzung von Hieronymus Wolf, welche auch Du Cange neben den Text gesetzt, zu trauen. Ganze Sãtze des Zonaras sind ausgelassen und andere dagegen aus dem Livius eingeschoben, - ein eutschieden tadelnswerthes Verfahren, wie apodiktisch auch Wolf es vertheidigt: Qui, sagt er in der Praef, interpretem huiusmodi salebras sine ullo sententiae detrimento vitantem, vel negligentiae, vel malae fidei accusant: suam vel inscitiam et iudicii inopiam, vel morbum animi et nulla de causa maledicendi libidinem produnt).

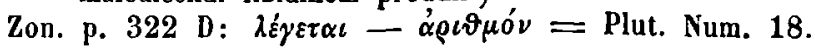


(Diese Stelle hat eine besondere Wichtigkeit, insofern sie Dinge enthalt, die nicht zur Sache gehören und deren Zusammenstellung subjectiv ist, dennoch aber, Geringfügigkeiten abgerechnet, wörtliche Uebereinstimmung bietet).

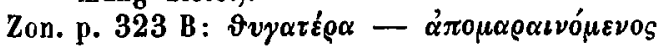
$=$ Plut. Num. 21 fin.

Von Tullus Hostilius bis auf Publicola verlässt ihn Plutarch; desshalb folgt er von p. 323 B - p. 336 B dem Dio. Wir haben die Uebereinstimmung dieses Abschnittes mit den Fragmenten des Letzteren oben dargethan. Nur Einiges scheint im Voraus aus dem Plutarch herübergenommen oder spăter nachgetragen, z. B. p. $325 \mathrm{D}$ cl. Plut. Public. 17.

Von p. $336 \mathrm{C}-$ p. 337 C ljildet der Publicola die265

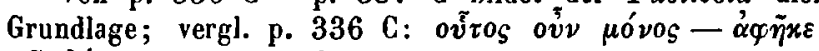
$\tau \tilde{\omega} \delta^{\prime} \eta^{\prime} \mu \omega$ mit Plut. Public. 10.

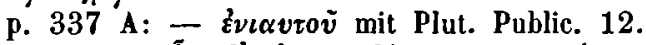

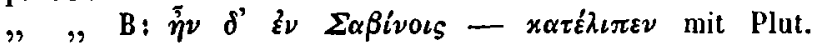
Public. 21.

(Hier eine Probe von der Kunst des Zonaras! Plu-

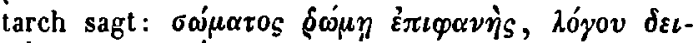

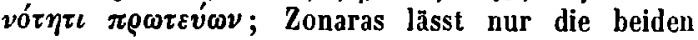
Epitheta ihre Plătze wechseln)

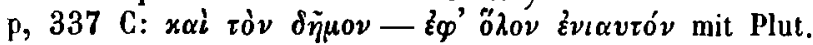
Publ. 23.

Von Publicola's Tode bis auf Camillus (p. $337 \mathrm{D}$ p. 352 A) ist nur Dio die Quelle; denn auch der Abschnitt p. 342 C - p. 344 B, der des Coriolan Geschichte enthält, zeigt nicht nur keine Wortähnlichkeit mit Plutarch's Coriolanus, sondern sogar in der Sache selbst viele Modificationen und Abweichungen. Vielleicht fehlte in dem unvollstãndigen Manuscripte, das Zonaras vor sich hatte, auch diese vita, so dass er auf Dio sich beschränken musste. Hierher gehörige Uebereinstimmungen siehe oben. Nur ein Beispiel von Gedankenlosigkeit! Wăhrend er p. 337 A den Marcus Valerius einen Bruder des Publicola genannt nach Plutarch, nennt er ihn jetzt p. 339 A nach Dio einen Gen- 
XXXIV Ueber die Quellen des Zonaras.

tilen desselben. Mit Recht klagt ihn hierüber Niebuhr an (T. 1. p. 599. n. 1197 ed. 3). Wenn Zonarás mit der

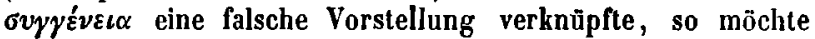
nach seinem Sinne zwar der Widerspruch nicht vorhanden sein; allein dann ist es Unwissenheil.

Von der ersten Dictatur des Camillus bis auf dessen Tod (p. 352 A - p. 360 C) zieht er beide Autoren fleissig zu Rathe. Mit dem Dio verglichen wir ihn schon; die Benutzung von Plutarch's Camillus bezeugen unter anderen folgende Stellen:

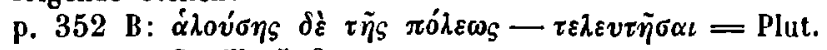
Camill. 5 fin.

(Dahingestellt lasse ich, ob die gleich hierauf folgende Abschweifung über den rômischen Triumph, bis p. $354 \mathrm{~A}$, aus Dio geflossen, oder ein selbststăndiger Zusatz sei).

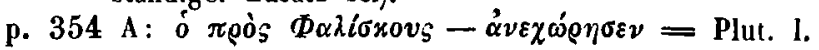
c. 9.10.

266 Diese Stelle gibt ein interessantes Beispiel, wie Zonaras die Angaben beider Quellen äusserlich mit einander verwebt. Leider ist das Fragment des Dio (28 ap. Reim.) nicht ausgedehnt genug, um das Ganze zu übersehen und den Zonaras b1s in die geringsten Einzelheiten zu controliren; indessen gibt die Vergleichung mit dem Vorhandenen einen partiellen Beleg für dıe Behauptung, dass Alles, was in den hier besprochenen Abschnitten nlcht aus Plutarch ist, dem

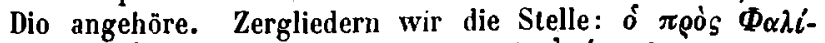

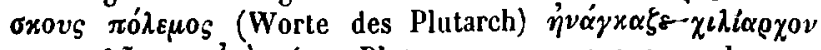
$\psi \eta \varphi \iota \sigma \vartheta \tilde{\eta} \nu \alpha \iota \alpha \dot{v} \tau \dot{\nu} \nu$ (aus Plut. zusammengezogen, oder aus

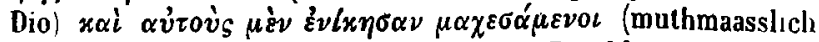
aus dem nicht vorhandenen Theil der Erzăhlung bei Dio).

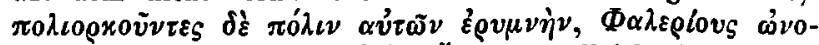

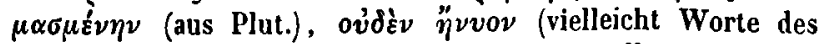
Dio oder auch eigenes durch die Sache selbst bediugtes

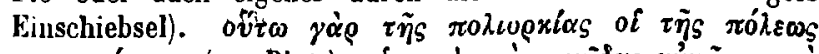

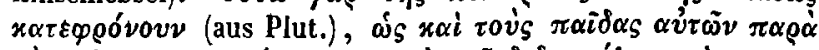

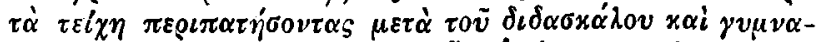

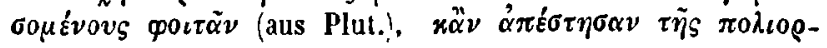


xi $\alpha$ s (sicher nach Dio, selbst wenn die Worte des Frag-

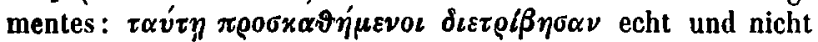
vielmebr als Uebergangsworte des Excerptors zu betrach-

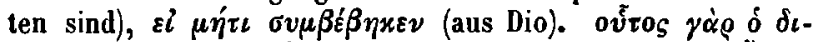

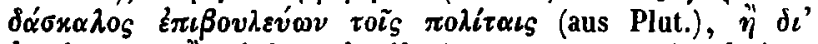

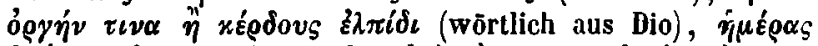

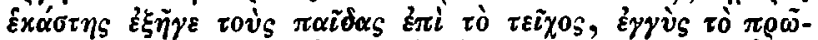

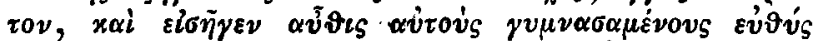

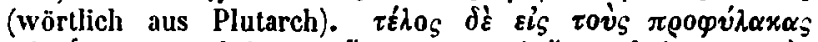

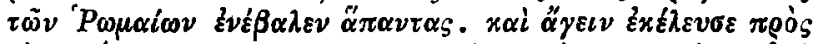

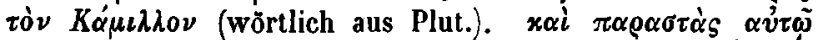

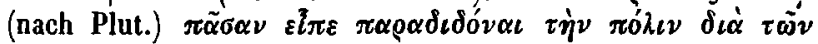

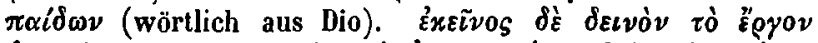

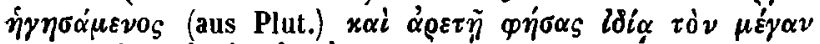

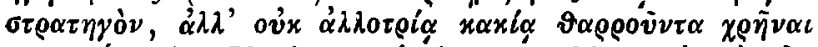

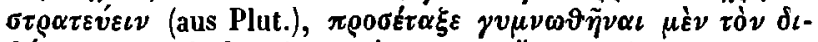

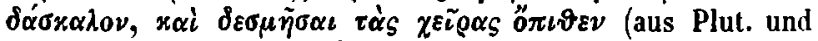

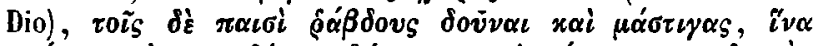

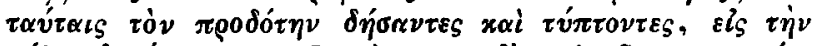

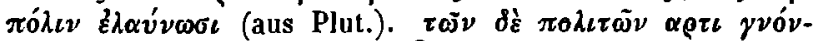

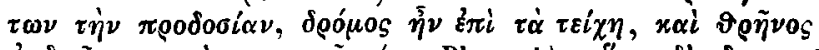

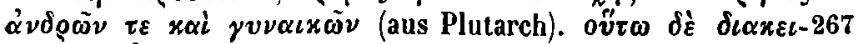

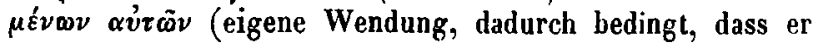
vorher ein tempus finitnm anstatt des Plutarchischen Genit.

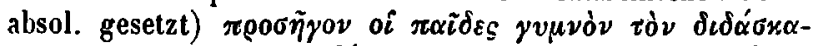

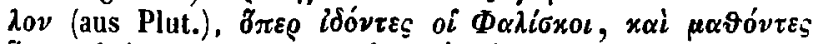

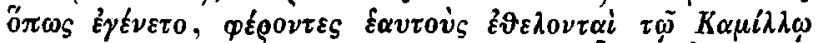

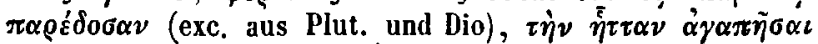

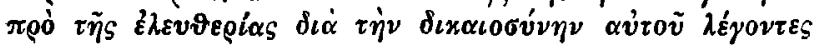
(aus Plut., die Beziehung der Rede vielleicht nicht ohne Rücksicht auf Dio modificirend). $\chi \rho \eta^{\prime} \mu \alpha \tau \alpha$ ov่ $\nu \lambda \alpha \beta \dot{\omega} v, x \alpha i$

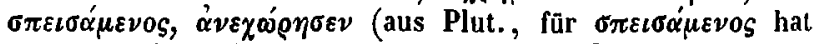
dieser $\varphi \iota \lambda l \alpha \nu$ จ์ $\varepsilon \varepsilon v 0 \varsigma$ ). - An anderen Orten sind übrigens die Angaben und Worte beider Quellen so in einander gearbeitet, dass man sie nicht mehr gehörig zu scheiden vermag. - Weiter:

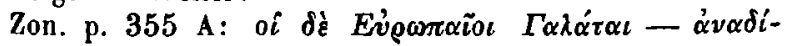
$\delta \omega \sigma \iota=$ Plut. l. c. 15. 
XXXVI Ueber die Quellen des Zonaras.

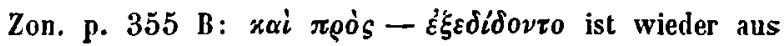
Plut. I. c. 17 und aus Dio fr. 141 zusammengesetzl, docl nimmt, wie oben, jener den ersten Rang ein.

Vom Tode des Camillus bis auf die Eroberung Korinths und Karthagos oder bis zum Ende des neunten Buches (p. $360 \mathrm{C}-$ p. $471 \mathrm{C}$ ) erscheint Dio als die ausschliessliche Quelle; denn meine Muthmaassung, Zonaras werde über den Tarentinisclıcn Krieg (p. 368 B-p. 378 D) den Pyrrhus des Plutarch, über den zweiten Punischen (p. 405 C-p. 443 D) dessen Fabius Maxımus und Marcellus, über den Macedonischen, über Cato und Nabis (p. $443 \mathrm{D}-449 \mathrm{~B}$ ), dessen Flaminius und Cato maior, endlich über den Krieg mit Perseus (p. 455 D-p. 460 B), dessen Paulus Aemilius zu Grunde gelegt haben, fand ich bei der Vergleichung nicht bestātigt. Es ist dasselbe Verhăltniss wie beim Coriolan; die gewöhnliche Wortăhnlichkeit fehlt, und nicht nur der ganze Guss, sondern auch theils die vielen $A b-$ weichungen und selbst Gegensătzlichkeiten in der Erzählungsweise, theils die Verschiedenheiten in der Anordnung der Thatsachen bezeugen einen anderen Ursprung. Unter die Abweichungen gehört auch in Bezug auf den Fabius Maximus, dass Zonaras den magister equitum durchweg nur Rufus benennt, nach Dio's Vorgange, während umgekehrt Plutarch durchweg Minutius sagt; in Bezug auf den Marcellus sehe man z. B. die Abweichung p. $425 \mathrm{D}$ cl. Plut. 1. c. 19. Dass der Paulus Aemilius des Plutarch durchgängig benutzt sei, hatte wohl einen Schein für sich; denn Zonaras citilt ihn gerade in dem betreflenden Abschnitte, wie wir oben sahen, und theilt dessen Worte mit (p. 559 B cl. Plut. l. c. 26). Allein bei einem Autor wie Zonaras, der factisch und grundsätzlich seine Quellen wòrtlich ausschreibt, isl-Nichtübereinstimmung der Worte schon en hinlānglicher Beweis der Nichtbenutzung; und nun macht eben hiervon die angezogene Stelle die einzige Ausnahme. Dagegen zeugen für den Dionischen Ursprung aller sonstigen Theile dieses grossen Abschnittes die nacligewiesenen vielen und auffallenden Uebereinstimmungen mit dessen Frag- 
menten. Es könnte daher sellost der Verdacht entstehen, jeues Citat sei aus Dio entlehnt, was an und für sich um so weniger unwahrscheinlich wăre, als Dio den vou ihm vielfach benutzten Plutarch mehr als einmal namentlich an-268 zog, wie wir diess aus den unzweifelhaft echten Fragmenten 38 und 133 ersehen. Doch ist einerseits die Uebereinstimmung mit Plutarch zu genau und verrăth eben mehr die strenge Manier des Zonaras, als die freiere Behandlungsweise des Dio, der, wie jene Fragmente darthun, selbst da, wo die Nennung des Namens ihm ein Recht zur Wörtlichkeit gibt, seine Quelle nur matt durch die umgewandelte Diction hindurchschimmern lässt (cf. Reim. praef. \$. 13); überdiess aber, sind gleich die dem Citate zunächst vorangehenden und folgenden Stellen sicher aus dem Dio gezogen, so scheint doch das hierhergehörige, von Mai entdeckte Fragment Nov. Coll. II. p. 546 zu beweisen, dass im Dio selbst jenes umfangreiche Citat nicht vorhanden gewesen sei. Steht also auch im Uebrigen die Nichtbenutzung des Plutarchischen Aemilius fest, so werden wir doch wohl glauben inüssen, dass Zonaras ihn um dieser vereinzelten Stelle willen durchmustert habe. Immer aber bleibt es seltsam, dass wir gerade $d a$, wo er ihn namhaft macht, erst einen Verdacht gegen die directe Benutzung zu überwinden genōthigt sind, und dass dagegen dieselbe gerade da klar am Tage liegt, wo er ihn nicht citirt.

Wăhrend also in dem vorhergehenden Abschnitte über Camillus der Text von Plutarchischen Phrasen wimmelt, ist Alles, was man, jenen Punct abgerechuet, in diesem grösseren wahrnehmen dürfte, ein äusserst spärlicher und schwacher Schimmer Plutarchischer Ueberlieferung, den man eben als solchen auf Dio zurückzuführen nach dem Gesagten nicht anstehen wird. So haben wir denn wiederum hier einen Beweis von des Zunaras Büchermangel oder von seiner Lãssigkeit, und dürfen überzeugt sein, dass auch der verlorene Scipio des Plutarch nicht in seinen Händen oder wenigstens nicht unter seinen Quellen war. Zugleich aber gewinnt nun die ganze Darstellung dieses Zeitraumes von Camill's Tode bis auf Karthago's Fall eine grosse Bedeutung 


\section{Ueber die Quellen des Zonaras.}

und Autorităt als Ersatz für die verlorenen Bücher des Dio, - ein sowohl wôrtliches, als umfangreiches Excerpt, 111 Foliospalten füllend. Doch wollen wir damit den Falconen nicht das Wort reden; denn ein Auszug aus einem Autor ist immer noch nicht der Autor selbst. Unser Resultat aber ist um so folgenreicher, je mehr wir in neuester Zeit über Dio's Quellen aufgeklärt worden (s. Wilmans de fontib. et auctor. Dionis Lassii. Berol. 1836), die zum Theil sehr wichtiger, originaler und archivalischer Natur waren.

Der Schluss des neunten Buches (p. 471 C D) enthält die Fortsetzung der in der Einleitung begonnenen Elegie. Zonaras klagt, dass er die Zeiten von der Zerstōrung Korinths bis auf die Kaisergeschichte nicht erzählen könne. "Aber beschuldige mich Niemand, sagt er, desshall der Geringschåtzung oder des Leichtsinns oder des Ueberdrusses; denn nicht freiwillig lasse ich das Werk halbvollendet, sondern aus Mangel an Büchern, die jene Zeiten umfassen. Ungeachtet meiner Forschungen und Erkundigungen konute ich sie nicht ausfindig machen, sei es, dass die Zeit sie zerstörte, oder dass diejenigen, welche ich mit der Nachsuchung beauftragte, da ich selbst íreóócos und fern von der Hauptstadt auf einer kleinen Insel lebe, sich nicht ge269hörig darum bemühten u. s. w." Er wendet sich nun zur Kaisergeschichte mit dem Versprechen: $\mu \iota x \rho \alpha ́$ $\tau \imath \nu \alpha \pi \rho o \delta \iota \eta-$ $\gamma \eta \dot{\eta} \sigma \sigma \vartheta \alpha \iota$. Wir sehen also, dass Zonaras nicht einmal sämmtliche Volumina des Dio in Hănden hatte, woraus Reimar folgert: eum (scil. Dionem), ut alibi, ita in his temporibus, quae a bello Punico tertio ad Pompeium pertingunt, iam olim hiatus ingentes habuisse (praef. ad Dion. \$. 14. cf. Du Cange ad Zon. p. 9), - noch die auf die ausgelassene Zeit bezüglichen Plutarchischen Biographieen der Gracchen, des Marius, Sulla, Sertorius, Lucullus, Crassus; woraus zugleich ersichtlich ist, dass er die vita des Pyrrhus, als welche mit der des Marius eine Parallele bildete, nicht benutzen konnte. Hătte nun aber Zonaras bei dem vorbesprochenen Abschnitte in der That mehr Quellen gehabt, als den Dio und Plutarch, wie Reimar p. XXI wăhnt, etwa den Appian und Aehnliche, so wäre es doch wahr- 
haft seltsam, wenn sie insgesammt hier dieselbe Lücke gehabt hătten. Von Polybius und Dionysius kann diess Argument freilieh nicht gelten, da ihre Werke überhaupt nicht über den dort behandelten Zeitraum hinausreichten.

Die Quellen des zehnten Buches (p. 472-545 C). Von der Ausbildung des Principates bis auf den Tod des Angustus.

Die Einleitung eröfhnet ein durchaus wortgetreues Excerpt (p. 472-491 D) aus dem Pompeius und dem Caesar des Plutarch, ohne dass die Quelle genaunt wird.

Zur Uebersicht.

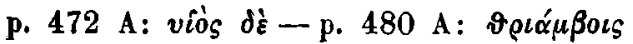
aus Plut. Pomp. $1-46$

p. 480 A: $\sum_{\iota} \operatorname{rod} \varepsilon i \alpha \varsigma-\vartheta \alpha^{\prime} \lambda \alpha \sigma \sigma \alpha \nu, \quad, \quad, 50$

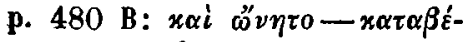

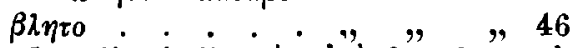

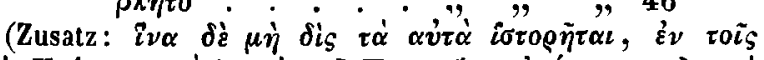

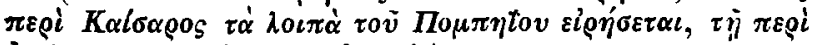

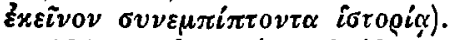

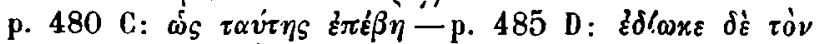

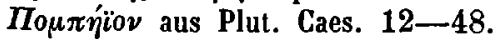

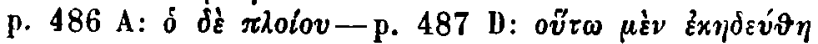
$\Pi_{0} \mu \pi$. aus Plut. Pomp. 73-80 med.

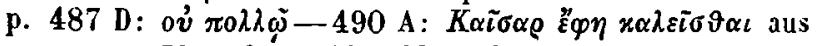
Plut. Caes. 48-60 med.

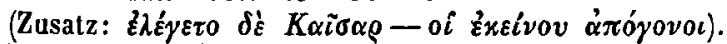

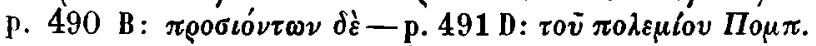
aus Plut. Caes. $60-66$ fin.

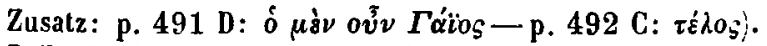

Beiläufig bemerke ich, dass bei einer Textrevision der Plutarchischen vitae die Zuratheziehung des Zonaras, die man bisher leider unterlassen, eine nicht zu verachtende Ausbeute gewăhren würde. Dass Zonaras p. 474 B, den Plutarch Pomp. c. 17 genau ausschreibend, Oppius setzt, wăhrend wir bei dem Letzteren selbst Appius oder Pius (Metellus) lesen, gehört zu dem Unbedeutenden. 
Von p. $492 \mathrm{C}-$ p. $305 \mathrm{D}$ nimmt er ausschliesslich den Dio vor, ohue es anzuzeigen; dann arbeitet er von p. 505 D-p. 544 anfănglich den Brutus und später den Antonius 270des Plutarch in die Dionische Grundlage hinein. Der Cato minor und der Cicero des Letzteren sind durchaus nicht gebraucht. Folgendes zur Uebersicht:

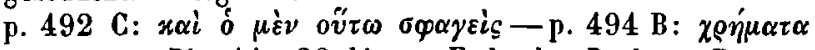
aus Dio 44, 20 bis zu Ende des Buches, Zonaras

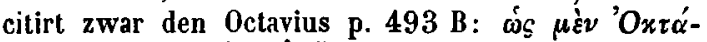

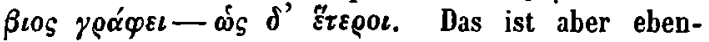
falls nur wörtlich aus der berühmten und schwierigen Stelle des Dio 44, 35 entlehnt.

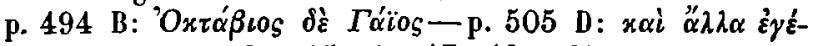
vero aus Dio 45, 1-47, 40. Gleich zu Anfange

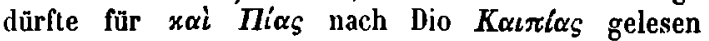
werden.

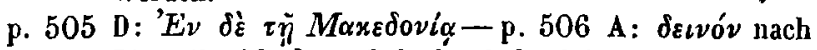
Dio 47, 40 fin. Jedoch sind einige Zusătze herübergeholt aus Plut. Brut. c. 39. Man sehe: $\dot{\varepsilon} \nu d \dot{\varepsilon}$

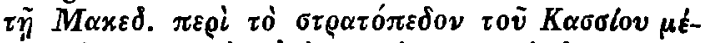

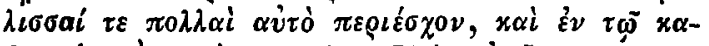

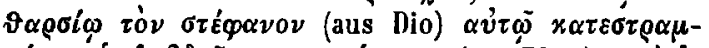

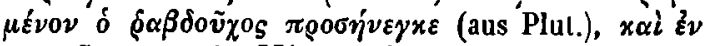

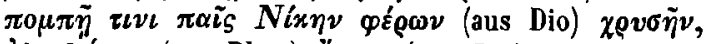
ò $\lambda \iota \sigma \vartheta \eta^{\prime} \sigma \alpha S$ (aus Plut.) $\varepsilon^{\prime} \tau \varepsilon \sigma \varepsilon$ (aus Dio) u. s. w.

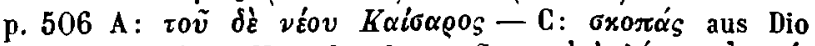

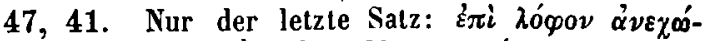

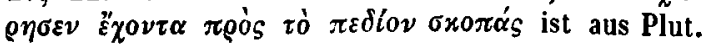
Brut. 43 hinzugefügt.

p. $506 \mathrm{C}: \dot{v} \pi 0 \tau 0 \pi \dot{\eta} \sigma \alpha_{S}-$ p. $508 \mathrm{C}: \alpha^{\prime} \pi \dot{\varepsilon} \vartheta \alpha \nu \varepsilon$ ist theils aus Dio 47, 46 med. bis zu Ende des Buches, theils aus Plut. Brut. $43-53$. Hier citirt auch endlich einmal Zonaras (p. 508 B) den Plutarch (s. Brut. 51) und den Dio (s. 47, 49).

p. $508 \mathrm{C}: \pi \varepsilon \rho i \tilde{\eta} \zeta-$ p. $509 \mathrm{~A}$ : $\varphi \alpha \nu \tilde{\eta} \nu \alpha \iota$ aus Plut. Brut.

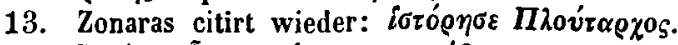

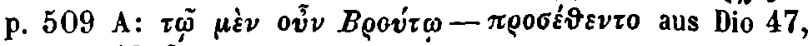
49 fin. 


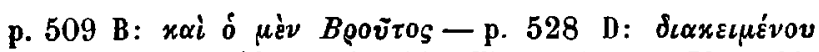
aus Dio 48,1-51, 10. Einiges ist aus Plutarch's Antonius herübergenommen, z. B. p. 512 D: $\tau \varepsilon-$

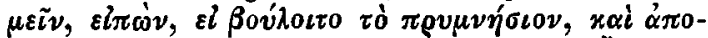
$\pi \lambda \varepsilon v \bar{\sigma} \alpha \iota$ cl. Plut. Anton. 32 ; p. 527 C: $\eta \dot{z} \varepsilon \times \beta \alpha-$

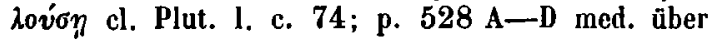
den Tod des Antonius ist ebenfalls nicht ganz nach Dio 51,10 , sondern verändert und ergänzt nach Plut. l. c. 77. 78. 79 .

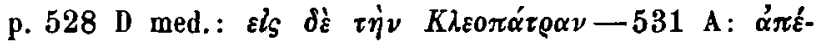

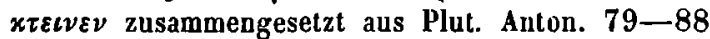
init. und Dio 51, 11-15 fin. Zon. citirt hier p. 530 A den Letzteren (s. 51, 14).

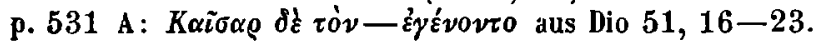
Nur die Angabe: II $\rho \varepsilon x o \mu i \sigma \vartheta \eta-\beta \rho \alpha i o \nu$ ist nicht sowohl aus Dio l. c. 21, als vielmehr aus Plut. Anton. 87.

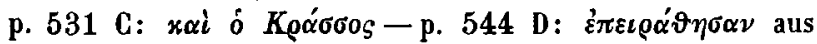
Dio 51, 23-56, 45 med., wobei Zonaras die Rede des Dio übergeht und nur eine kurze Inhaltsanzeige gibt.

Plutarch's Biographieen der Kaiser sind, wie es scheint,271 gar nicht in seinen Hãnden gewesen; vielleicht waren sie schon damals bis auf Galba und Otho verloren; benutzt hat er diese Letzteren wenigstens nicht (s. weiter unten); und dasselbe lässt sich auch von dem Augustus um so zuversichtlicher voraussetzen, als, anderer Gründe nicht zu gedenken, die wenigen Differenzen zwischen Zonaras und Dio meist sehr geringfügig und leicht erklärbar sind; z. B. p.

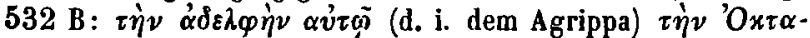
$\beta i \alpha \nu \sigma v \nu \omega^{\prime} \iota \sigma \varepsilon$ - ein Missverständniss, das er mit Xiphilin theilt; Dio 53,1 sagt $\alpha \delta \varepsilon \lambda \varphi \iota \delta \tilde{\eta} \nu$ und meint die Mar-

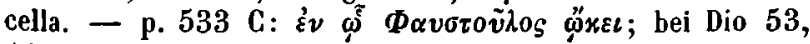
16 lesen wir: Romulus. Selbst dem genauen Reimar scheint diese Abweichung entgangen zu sein; nach der Anuahme des Alterthums war übrigens Beides richtig, und da Zonaras die Geschichte des Romulus noch frisch im Gedächtniss haben musste, so ist die Modification um so weniger auf- 
fallend; dennoch könnte man auch an Corruption denken.

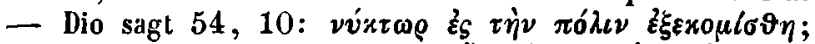

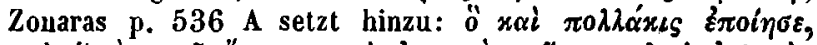

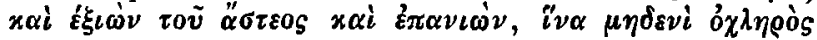
$\varepsilon i \eta \eta$. Dieser Zusatz, der zwar im Itio vorkommt, aber an einer anderen Stelle, scheint zu beweisen, dass Zonaras neben dem Dio hier auch den Xiphilin zur Hand gehabt; denn in dessen Auszuge finden wir an dem nämlichen Orte dieselbe Phrase mit geringer Aenderung (cf. Reim. ad Dion.

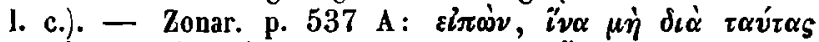

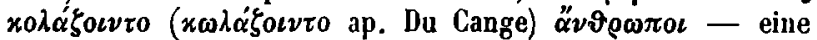

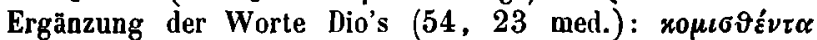
$\sigma v \nu \tau \varrho \iota \beta \dot{\eta} \nu \alpha \iota$ éx $\varepsilon^{\prime} \lambda \varepsilon v \sigma \varepsilon \nu$. Die Anfangs von mir gehegte Ansicht, dass Erweiterungen, wie sie diese und die meisten der noch anzuführenden Stellen zeigen, aus Plutarch's Augustus geflossen sein möchten, glaube ich nicht hinlänglich begründen zu können und bin jetzt vielmehr geneigt, Allés der heutigen Lückenhaftigkeit des Dio zur Last zu le-

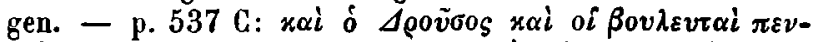

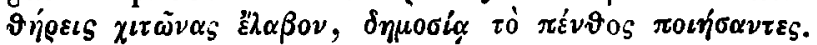
Diese Angabe dürfte aus einem Nissverständnisse bei Benutzung des Dio 54, 35 fin. hẻrgeleitet werden. - p. 539

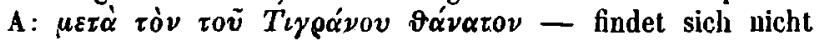
bei Dio 55, 9 med., gehört aber wahrscheinlich, sowie das:

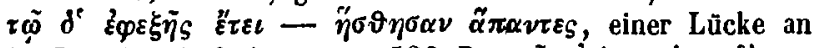

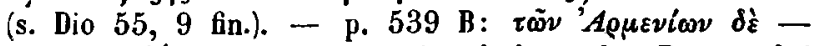
$\pi \alpha \tilde{i}_{S} \nu 0 \mu \iota \zeta o ́ \mu \varepsilon \nu 0 \varsigma$ - ein höchst bedeutender Zusatz; bei

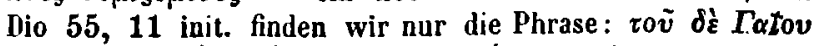

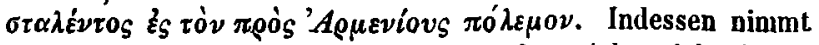
auch hier Reimar eine Lücke an, oder sieht vielmehr in Dio's Worten die Zusammenziehung eines Abschreibers, was er durch ein, wie es scheint, hierher gehöriges Fragment aus den Exc. Peir. zu erhärten sucht, sowie durch den Umstand, dass alles Vorhergehende und Nachfolgende beim Zonaras ganz wörtlich aus Dio entlehnt ist. Dagegen liesse sich zwar einwenden, dass einerseits zwischen jenem Fragmente und der Stelle des Zonaras nicht der leiseste An272klang herrscht, und dass wir ja auch sonst hăufig die Be- 
merkung gemacht, wie Zonaras eine Plutarchische Stelle zwischen zwei Dionische einschiebt; allein jenes Fragment, nur wemige Zeilen lang, könnte von dem excerpirenden Zonaras gerade übergangen seın, und Anzeichen für die Benutzung einer anderweitigen Quelle in diesem zuletzt angegehenen Abschnitte über Augustus kommen eben, so wenıge und missliche Puncte abgerechnet, gar nicht vor. Dass aber im 55. Buche des Dio und in den folgenden überhaupt viele Lücken und Zusammenziehungen sind, kann durchaus nicht gelăugnet werden; schon Xylander (ad Divn. p. 556) hat es dargethan, und ich verweise nur auf Zon. p. 540 B:

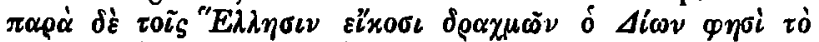
$\chi \varrho v \sigma o v i v \alpha^{\prime} \lambda \lambda \alpha^{\prime} \sigma \sigma \varepsilon \sigma \vartheta \alpha \iota$ vó $\mu \iota \sigma \mu \alpha$ - also auf einen am meisten in die Augen fallenden Beleg; denn das Gesagte finden wir beı Dio 55, 12 nicht, wāhrend er im zunächst Vorhergehenden völlig mit Zonaras übereinstimmt. Es ist klar: das Exemplar, das Zonaras benutzte, enthielt mehr als die unsrigen; und nicht nur vom 55. Buche erst möchte ich diess gelten lassen, sondern auch schon vom 54.*) Die

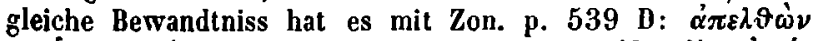

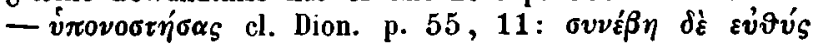
und vielen anderen Stellen, worüber man deı Reimar consultiren mag, der in dieser Beziehung mit seltener Genauigkeit verfährt.

Von p. $544 \mathrm{D}: \dot{\varepsilon}^{2} \nu \delta \dot{\varepsilon} \tau \tilde{u}-$ p. $545 \mathrm{C}$ oder bis zum Ende des Buches ist ein Zusatz über die Geburt Christi aus Euseb. hist. eccl. I. 5. 9, den er selbst citirt, im Vergleich mıt dem, was er p. $543 \mathrm{C}$ über die Regıerungsdauer des Augustus nach Dio gesagt, welchen er durch die Worte:

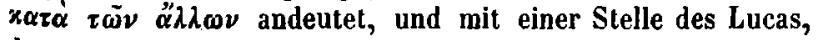
den er wieder namhaft macht.

*) Mai sagt l. c. p. 197: Exin (a XXXVI) Dionis libros usque ad LIV aiunt esse integros eruditi, cui tamen adfirmationi sine dubio derogare fidem licet, quoniam Dio tantopere tamque varie in codicibus vexatus apparet. Deinde libros a $L V$ ad $L X$ passim adhuc mutilos esse videmus. 
273 Die Quellen des elflen Buches (p. 545 C-p. 592 D).

Von Tiberius bis Antoninus.

Das Ganze ist aus Dio L. 57 init. - L. 69 fin. Mit deu anscheinenden Zusätzen verhält es sich wie oben z. B. p. 548 B, was bei Dio 57, 16 fin. heute vermisst wird; über p. 557 sq. s. Reim. ad Dion. 59, 25 fin. Ein schla-

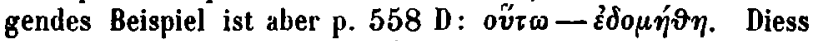
ist in den Codices des Dio $(59,28)$ in wenige Worte zusammengefasst. Nun ist jedoch ein Fragment in den Exc. Peir. 670 vorhanden und von Reimar schon am gehörigen Orte eingeschaltet, welches mit Zonaras vollkommen übereinstimmt. Ebenso p. $56+$ cll. Exc. Peir. p. 674 ap. Reim. 60, 31. Vergleiche üherdiess p. 557 B C D mit Nov. Coll. Il. p. 204 sq. - und pp. 565 D. 566 A mit Nov. Coll. p. 208 sq.

Vom 61. Buche an, wo die Codices des Dio abbrechen, haben wir die Vergleichung mit Xiphilin's Excerpten angestellt. Sie genügen vollkommen, die umfassende Benutzung auch dieser verlorenen Bücher darzuthun; sie waren für Zonaras gewissermassen die einzige Quelle. Da versteht es sich denn auch von selbst, dass Anführungen, wie: Étç̨o $\delta \varepsilon \dot{~ y o \alpha ́ q o v \sigma \iota ~ u . ~ s . ~ w . ~ w i e d e r ~ n u r ~ A f l e c t a t i o n ~ s i n d . ~}$

Nachlässigkeiten im Abschreiben kommen natürlich ōfters vor, sie sämmtlich zu berühren ist nicht meine, sondern des Commentators Sache. Hier nur ein Beispiel, P.

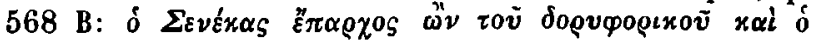

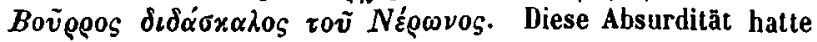
natürlich Dio nicht; doch waren bei ihm, wie aus Xiphil. 61,3 hervorgeht, die Worte so gestellt, dass ein Unwissender sie freilich missverstehen und verdrehen konnte,

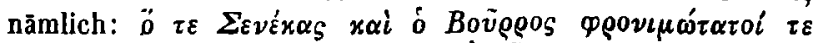

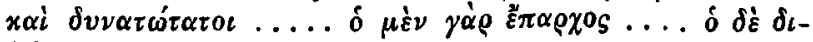
$\delta \dot{\alpha} \sigma x \alpha \lambda 0 \varsigma$ x. $\tau . \lambda$.

Am Ende fast jeder Regierung hängt Zonaras eine Relation über die Verhăltnisse der Clıristenheit au, - eine Art kirchlicher Statistik mit besonderer Rūcksicht auf die Succession der Bischöfe. Diese ist jedesmal aus der Kir- 
chengeschichte des Eusebius gezogen. Ein Beispiel sahen wir schon am Ende des 10. Buches beim Tade des Auguslus. Wir finden deren ferner:

Nach der Geschichte des 'Tiluer. p. 552 A-D v. fin.274 aus Euseb. I. 10. II. 2 (den Tertullian hat Zonaras nicht); nach der des Caius und Claudius p. 567 C-p. 568 A med. $\Longrightarrow$ Euseb. II. 11. 13-15 (aus ihm sind die Zeugnisse des losephus, Lucas und Iustinus Martyr entlehnl); über die Christenverfolgungen unter Nero p. $570 \mathrm{~A}=$ Eus. II. 26. III. 2 (mit geringer Morlification); nach Domitian p. 582 sq. $=$ Eus. III.

Genug, Alles was auf das Christenthum sich bezieht, ist aus diesem Autor entnommen. S. noch p. 591 b s 4 . cll. Euseb. IV. c. 4 sqq. Das Citat des Iustinus Martyr ist ebenfalls aus c. 10 extr. und c. 11. - Zuweilen sind Eusebius und Dio in einander goarbeitet, 2. B. p. $587 \mathrm{~A}-$ p. 588 A cll. Euseb. IV. c. 1 sq. III. c. 32 sqq. und Dio (Xiphil.) 68, 32 sq. Nur den Ersteren nenut Zonaras, den

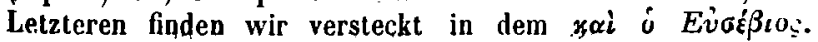

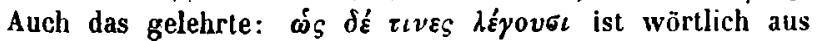
Dio. Uebrigens aber citirt Zonaras auch diesen an verschiedenen anderen Orten des Abschnittes, wie p. 590 C. (cf. Xiphil. 69, 15).

Wir müssen eipige besondere Puncte besprechen.

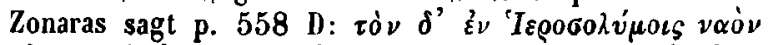

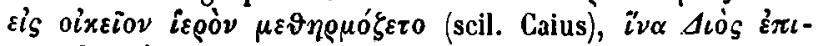

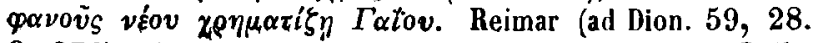
\$. 276) scheint zu glauben, er habe das aus dem Philo (de legat. ad Caium p. 804 ed. Turneb. p. 731) abgeschrieben; quae, sagt er, assuit Zon. totidem verbis ex Philonis loco petita sunt. Schon vor ihm Du Cange ad Zon. not. hist. p. 21: quod hausit Zon. e Philane. Dem ist nun aber nicht so. Allerdings sierd es zwar die Worte des Philo, jedoch nicht unmittelloar aus diesem selbst entlehnt, den er nie vor Augen gehabt, sondern nur wieder mittelbar aus Eusebius (hist. eccl. II. 6). Im Iosephus steht die Notiz uicht, was auch dessen Abkürzer Zonaras bemerkt. Wer kann nun aber unter so bewandten Umstănden stelem 
Misstrauen wehren? Sicher verhält es sich ähulich mit deu Citaten aus Appian: p. 575 D und p. 584 D. Beide sind ohne Zweifel aus Dio herübergetragen; von dem Ersteren werden wir nachher sprechen; das Letztere betriff die Orthographie $\Delta \alpha \dot{x} \alpha \alpha_{\xi} \ddot{\eta} \Delta \alpha x o v_{\zeta}$. Dass der genaue Dio diese philologische Bemerkung macht und durch das Zeugniss des sicher von ihm hăufig benutzten Appian unterstützt, ist weit glaubwürdiger, als dass Zonaras, der den Appian sonst durchaus nicht gebraucht, um dieser unbedeutenden Bemerkung willen ihn aufgeschlagen baben sollte, wenn er ihm auch wirklich zugänglich gewesen wäre, was doch aus früher angegebenen Gründen als unwahrscheinlich sich ergab. Ueberdiess ist die ganze Periode, in deren Mitte die Notiz steht, in der That wörtlich aus Dio (cf. Xiphil. 68, 6). Ebenso ist ohne den geringsten Zweifel das Citat aus dem Philostratus im Leben des Apollonius von Tyana (Zon. p. 582 A) ein aus Dio gestohlenes. Dass wir es bei Xiphilin nicht finden, beweist Nichts; denn alle Citate werden von ihm ausgelassen. Dagegen ergibt sich bei einer Vergleichung mit demselben $(67,17.18)$ sowohl alles Vorhergehende und Nachfolgende, als auch die in Rede stehende Erzăhlung selbst, Satz für Satz, ja fast Wort für Wort, als eiı Plagiat aus dem Dio. Danach hege ich die Leberzeugung, dass auch das zweite Citat aus dem Philo-

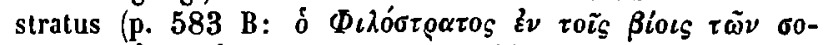
$\varphi \iota \sigma \tau \tilde{\omega} \nu \alpha \nu \varepsilon \gamma \varrho \alpha \dot{\alpha} \alpha \tau o$ d. i. 27 p. 546 c. d) aus Dio herzuleiten ist. Wie sollte Zonaras, der nicht einmal die allgemeineren Werke gehörig benulzt, seine Augaben aus Specialschriften, aus ganz fernliegenden literarischen $\mathrm{Ab}$ handlungen mūhsam zusammengesucht habeu! Andrerseits hatte Dio diese Anekdote rum Schatze des Alticus gewiss nicht übergangen (Xiphilin gibt über Nerva ein höchst mageres Excerpt 68, 1-3), und den Namen des Gewăhrsmannes um so eher angeführt, als die Erzăhlung von ăusserst wenigen Schriftstellern überliefert worden zu sein scheint; unter denen, die wir besitzen, ist Philostratus, so viel ich weiss, der Erste. Hierzu kommt wiederum, dass alles Voranstehende und Folgende theils aus Dio, theils aus 
Eusebius ist. Dreser Letztere aber schweigt, und so erscheint Jener nothwendio als der Beraubte. Dass Dio beile Werke des Philostratus benutzte, zeigt sich schon aus Reimar's Zusammenstellungen in den Noten hinlänglich. Zonaras aber beweist, dass das industriōse Handwerk, mit fremden Federn sich zu schmũcken und eine erborgte Gelelirsamkeit mit grosssprecherischer Affectation zur Schau zu tragen, nicht erst eine Erfindung der Neueren ist.

Der Abschnitt von der Empōrung des Vindex bis auf den Untergang des Vitellius (p. 570 B-p. $576 \mathrm{C}$ med.), dessen specielle Betrachtnug erst die vorliegende Abhandlung veranlasste, $\left.{ }^{*}\right)$ ist ebenfalls, Geringes ausgenommen, aus Dio $(63,22-65,22)$ entlehnt. Wichtig ist es in dieser Beziehung, dass Zonaras den Vindex Caius neunt; denn Dio ist in der 'That der einzige unter allen alten Schriftstellern, der demselben diesen Beinamen gibt. Zonaras citirt auch p. 575 A den Dio (cf. 65, 8). Eine eigentliche Vergleichung würde hier zu weit führen; ıch verweise nur auf Reimar. Dass Zonaras übrigens den Dio selbst, nicht den Xiphilin excerpirt, wird durch die vielen Stellen dargethan, wo er ausführlicher spricht, als Xiphilin, oder

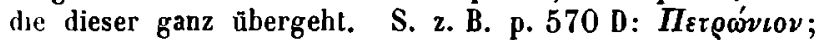
Xiphilin 63, 27 deutet diesen nur durch das ä $\lambda \lambda_{0} v_{S}$ an. Doch scheint auch die Benutzung des Xiphilin sowohl aus früher Gesagtem, als daraus hervorzugehen, dass ihre bei-276 derseitigen Auszūge oft Wort für Wort übereinstimmen, z. B. p. 572 B. cl. Xiph. 64, 6; sie müssten denn Beide gerade an solchen Orten den Dio nicht eigentlich abgekürzt, sondern abgeschrieben haben. - Nur Einiges zieht Zonaras wieder aus dem Iosephus, den er auch citirt (p. $575 \mathrm{~A}$ und C), Einiges aus dem Eusebius, ohne ihn zu nennen (p. 575 D. cl. Euseb. hist. eccl. III. 8, 5); die Verẃeisung auf Appian

*) Des Vf's Absicht war damals eine Geschichte jenes Zeitraums oder des ersten Jahrhunderts der Kaiserzeit mit amfassenden Quellenuntersuchungen herauszugeben; davon ist indess wenig mehr als der culturhistorische Theil "Gesch. der Denk- und Glaubensfreiheit im ersten Jahrb. der Kaiserschaft" (1847) an's Licht getreten. 


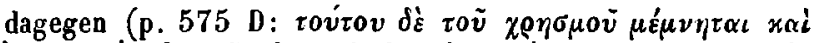

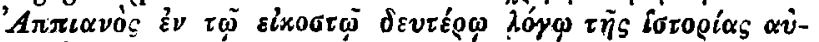

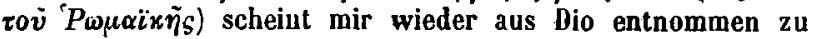
sein. Eusebus wenigstens hat diess litat nicht, und dass Zonaras gerade nur dieses Buch des Appian in Händen gehaht, ist unwahrscheinlich. Doch dürfte er auch die Bemerkung als Randglosse zu Dio $(66,1)$, Eusebius oder Iosephus gefunden haben. - Den Galba und Otho des Plutarch hat Zonaras so wenig wie dessen übrige Kaiserbiographieen benutzt; denn gerade die Stellen, die wir im Xiphilin nicht finden und von denen man also muthmassen dürfte, dass sie aus Plularch wären, finden sıch auch bei dıssem nicht, z. B. p. 570 C, p. $572 \mathrm{~A}$; daher muss man auch bei ihnen eınen Dionischen Ursprung voraussetzen, und dass Xiphilın sie nur übergangen; sowie die bei dem Letateren ebenfalls fehlende und auch sonst nirgend vorkommende Angabe des Zouaras p. 571 D (über die Sklaven) sich jetzt durch Vergleıchung mit dem Fragmente: ó $\iota \iota \tau \iota \nu \dot{s} \boldsymbol{x}$. $\tau$. $\lambda$. (Nov. Coll. p. 216) bei einiger Combination als Dionisch ergibt.

Die Quellen des zwölfien Buches (p. 592 D-p. 648).

Von Antoninus Pius bis auf den Tod des Maximinus.

Ueber Antoninus (p. 592 D - p. 593 D) sind die Quellen offenbar Xiphilin und einige Fragmente des Dio (s. Xiph. $70,1-4$ fin. und Reim. ad II. cc. und ad 71,32 fin. \$. 130). Die Sache hångt wohl so zusammen: In den Exemplaren des Dio war eine Lücke, die nach Xiphilin's Angabe sich über Antoninus Pius und den Anfang der Geschichte des Marcus erstreckte; Xiphilin füllt sie durch einige Angaben aus Eusebius und Quadratus aus. Dieselbe Lücke fand nun auch Zonaras in seinem Dio; desshalb schrieb er die wenigen Notizen des Xiphilin wörtlich ab. Jedoch fanden sich in seinem verstümmelten Exemplare noch einige Fragmente vor, welche in dem des Xiphilin nicht vorhanden gewesen sein müssen, weil dieser sie weder mittheilt noch verarbeitet, auf die aber Dio, wenigstens auf eins derselben, augenscheinlieh anspielt is. 71,32 fin.). 
Sie beziehen sich auf die Lücke im Aufang des Marcus; der unwissende Zonaras jedoch bezog sie auf Antoninus Pius und schob sie unter die Notizen des Xiphilin: $\mathrm{p} 503 \mathrm{~B}$ :

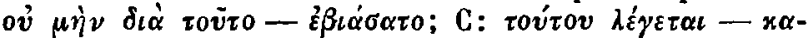

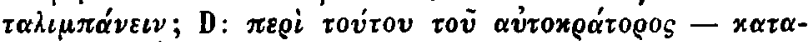

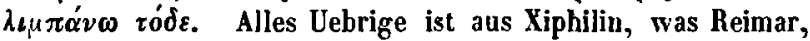
so viel ich weiss, weder ausspricht noch andeutet; es kann aber nicht anders sein; deun wenn auch Zonaras in seinem Dio das finden mochte, was Yiphilin 70, 1. 2 fand, so könnte doch, was dieser c. 3. 4 aus eigenen Mitteln selbststāndig zusammenträgt, nicht im Zonaras so wörtlich sich wiederfinden - ohne Benutzung. Nur den Eusebius hat277 auch Zonaras zur Hand und excerpirt ihn, ohne shn namhaft $z u$ macben, in dem kirchengeschichthchen Anhange p. 594 A - C; vgl. Eus. IV. 10 sqq.

Aus gleichen Gründen 1st auch der Anfang vom Marcus Aurelius p. 594 C, weil er wörtlich mit Xiphilin übereinstimmt, im Dio aber fehlte, nothwendig aus dem Ersteren $(71,1 \mathrm{sq}$.$) . Im Verlaufe nimmt man jedoch an eini-$ gen Erweiterungen und an mehrfachen citaten aus Dio (p. 595 C D. p. 596 A. fl. 607 D. p. 608 A [cf. Xiph. $75,13]$ ) wahr, dass Zonaras, sobald die Lücke erganzt war, auch wieder den Dio selbst zur Hand nahm. Er benutzt ihn unuuterbrochen bis p. 619 A (cf. Xiph. L. 71 -80 fin.), beiläufig nur den Eusebius in christlichen Dingen: p. 595 D, p. 597 B, p. 600 D sq. (cf. Eus. V. 9 sqq.), p. $610 \mathrm{C}-$ p. $612 \mathrm{~A}$ (cf. Eus. Vl. 1 sqq.), p. 618 A (cf. Eus. VI. 21). Mitten in der Geschtchte des Alexander Severus verlâsst ihn Dio, und er ist genōthigt, sich nach einem anderen Führer umzusehen.

Von p. $619 \mathrm{~A}-$ p. 648: von Alexander Severus bis auf Maximinus, Licinius und Constantin.

Wer ist nun dieser neue Führer? - Nicht die ermüdenden, oft fruchtlosen, Forschungen will ich miltheilen, sondern wie im Bisherigen nur der Mühe Ergebnıss. Der vorliegende Abschnitt, wie schon, ohgleich in geringerem Maasse, die zunächst vorhergehenden, sondert sich in zweı wesentliche Bestandtheile: die politische und die Kirchen- 
Geschichte. Für jeden folgt Zonaras Einem Hauptgewährsmanne, hier dem Eusebius, dort, wie mir scheint, dem anonymen Fortsetzer der Geschichte des Dio bis auf Constantin, aus welchem uns Mai in der Nov. Coll. II. p. 234-246 einige Excerpte geretlet hat. Wăhrend ich nirgeud bei theilweise oder vollständig vorhandenen Autoren, wie Dexippus, Eunapius, Zosimus, Malalas, Cedrenus, das Chronikon Paschale u. s. w. eine directe Quellenbeziehung auffand, zeigen sich hier merkwürdige Spuren und überraschende Uebereinstimmungen in Angaben, die bei dem jetzigen Bestaude der Quellenliteratur für diese Periode als entlegen und isolirt gelten dürfen. So sagt z. B. Zonaras von Ae-

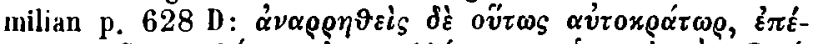

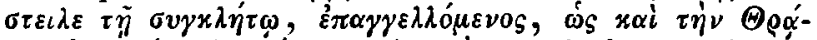

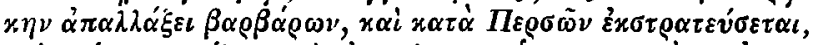

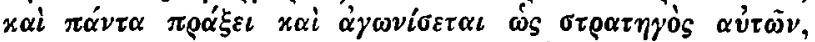

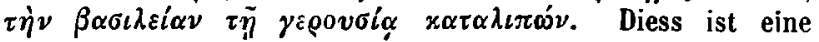
vereinzelte Notiz. Nun finden wir die Quelle in einem Frag-

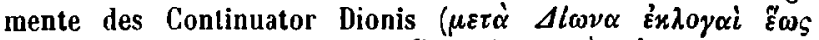

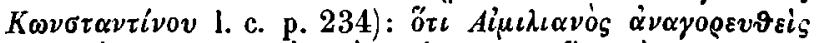

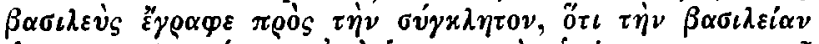

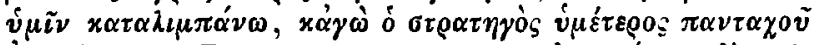

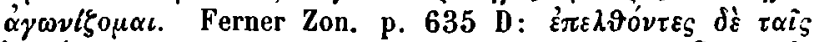

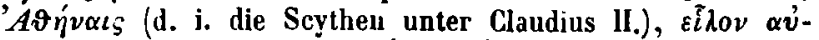

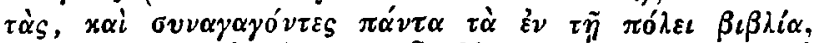

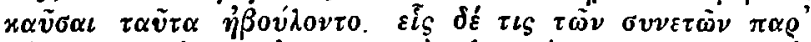

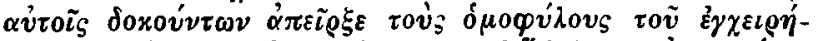

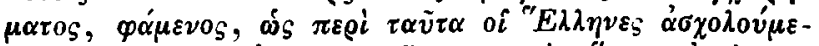

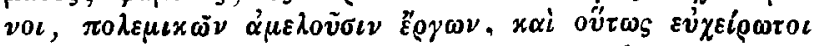
yívovta. Dasselbe lesen wir im Anonymus 1. c. p. 240:

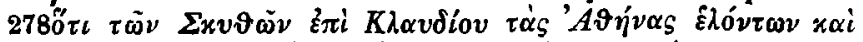

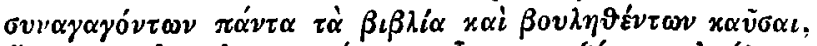

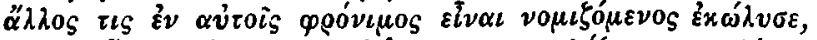

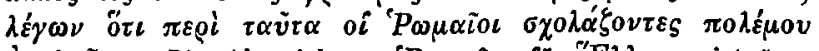

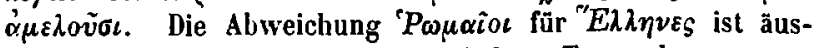
serst unbedeutend; im ursprūnglichen Texte kann sogar Beides gestanden haben, wie dewn auch der Verfasser gleich in den folgenden Worten eine Anwendung des Erzählten 
auf die Athener und die Römer zugleich macht. - End-

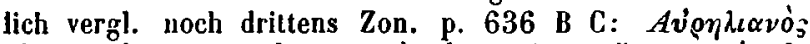

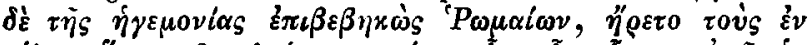

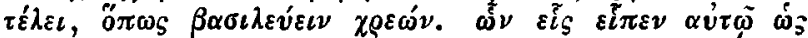

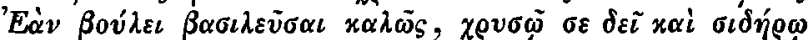

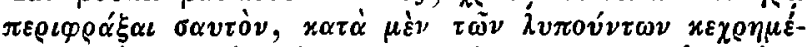

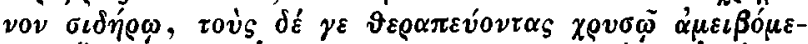

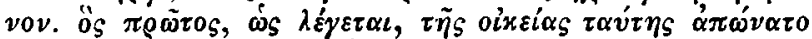

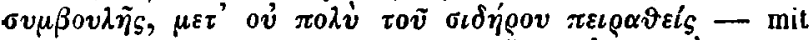

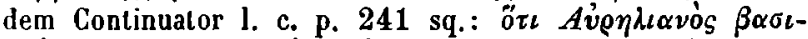

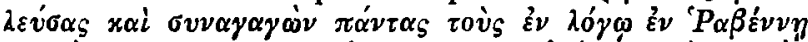

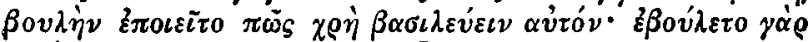

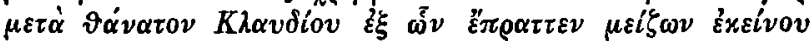

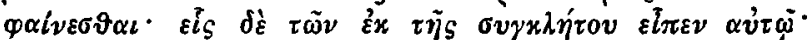

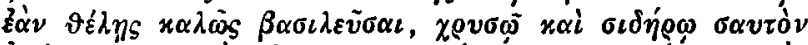

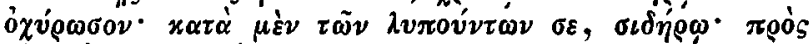

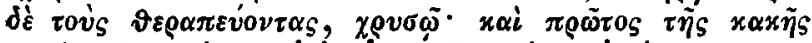

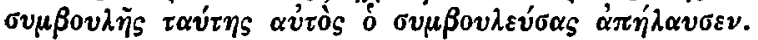

Sind nun alle politische Nachrichten des in Rede stehenden Abschnittes auf diese Quelle zurückzuführen, so steigert sich der Werth durch die Gewissheit, dass derselben glaubwürdige Primărschriften zu Grunde liegen. So sehen wir gleich von da ab, wo Dio's Nachrichten abbre-

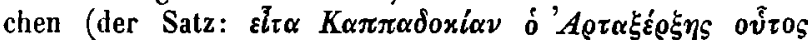

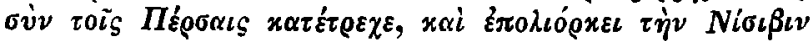
scheint nuch dem Dio anzugehören, obgleich ihn Xiphilin übergeht), durch des Zonaras Darstellung einen Herodianischen Schimmer hindurchblicken; man vergleiche nur $p$. 619 A - p. 620 A med. mit Herodian. VI. 4-9 fin., und auch das Weitere bis auf die Zeit Gordian's III. (p. 622 D) mit dem Reste des Herodianischen Werkes. Doch darf man nicht etwa in diesem Letzteren eine unmittelbare Quelle des Zonaras finden wollen, weil dessen Erzählung nicht völlig darin aufgeht, weil im Guss der Worte nicht hinreichende Anklänge sich zeigen, und weil endlich Zonaras zuweilen abweicht oder über Dinge in $\mathrm{Zweifel}$ ist, über die ihm Herodian Aufschluss gegeben hätte. So nennt er den Mitregenten des Maximus nicht Balbinus, sondern Albinus 
(p. 621 sq.) und schiebt gleich darauf zwei Kaiser in dice

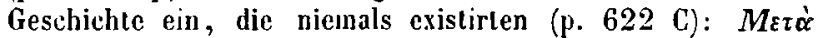

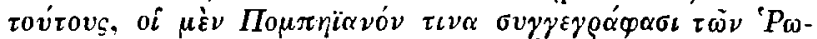

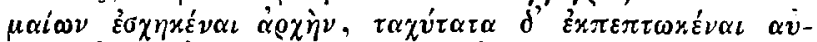

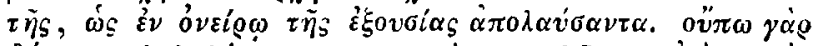

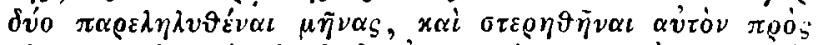

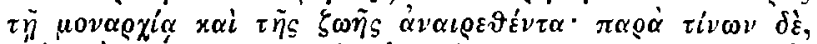

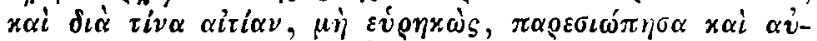

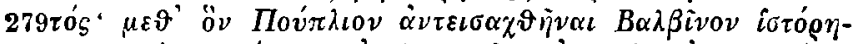

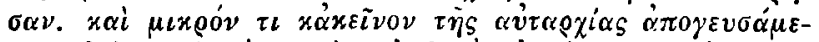

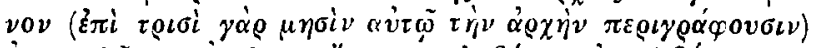

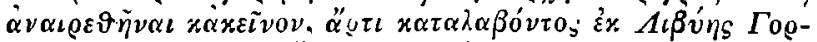

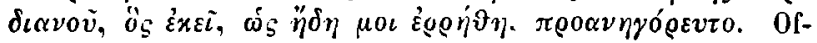
fenbar liat Zon. hier einen Chronisten zur Hand (welchen, weiss ich nicht), den seine Unwissenheit nicht zu benutzen

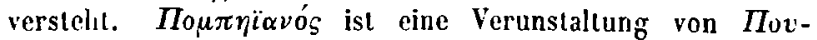

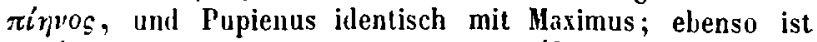

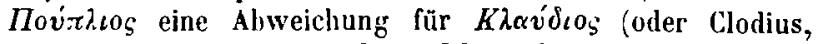
oder Cãcilius. S. Victor Caes. 26, wobei eine Vereinigung möglich), und Balbinus identisch mit Albinus. Diese Verdrehungen konnten auch schon in jenem Chronisten vorhanden und bei der Kürze verfänglich sein. Dass ülıer diesen Zeitpunct bei den Späteren Verwirrung geherrscht, beweist das Chron. Paschale (vergl. auch Zosim. p. 17 ed. 0xon., wo ein Sabianus oder Sabinianus erscheint). Die Beziehung der Angabe des Zon. auf den Consul Pompeitnus Givica (Du Cange not. hist. p. 25) ist ein gezwungener und völlig eiteler Rettungsversuch. Jedenfalls stehe ich an, die Verwirrung auf den Contin. Dionis selbst zurückzuführen, der ohne $\mathbf{Z}$ weifel wie IIerodian auf Maximus und Albinus oder Balbinus unmittelbar Gurdian III. folgen liess. Wemn gleich daher diesem Zon. das Meiste verdauken már, so will ich nicht in Albrede stellen, dass er auch sonst hier und da einen oder den anderen der Chronisten, deren Werke damals in Jedermanns Händen waren, verglichen haben könne, wesshalb ich auch Qucllenandeutungen wie: ís ó Evंoźp $\beta_{\iota \circ}$

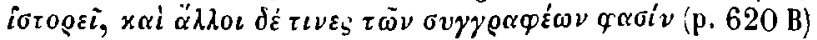
in diesem Abschnilte nicht inmer für trügerisch halte (cf. 
p. 621 D, p. 622 C D, p. 623 A, p. 627 D, p. 636 B, p. 644 B). Dahin gehôrt nun wohl zunäclıst die Clıronik des Eusebius selbst, die Zon. sicher auch jetzt noch zu Rathe zog, wse dıe Anführung über des Claudius Regierungszeil p. $636 \mathrm{~B}$ cl. Euseb. Canon. p. 392 ed. Mai et Zohr. darthul; denn in der Kirchengeschichte erwăhnt Eusebius den Claudius gar nicht, so dass das Cital durchaus nicht falsch bezogen werden kann. Auch im kirchlichen Theil scheint Zon. Manches aus dessen Chronik vervollstăndigt zu haben. Leider bricht der armenische Codex in der Chronographie mit lutius Câsar ab; dass Eusebius die Kaisergeschichte nicht ausgelassen, erhellt schon aus dem Prooem. c. 4 fin.: tum et eos (sc. explicabo), qui post Iulium Caesarem atque Augustum rccta serie fuerunt imperatores; denıque et annuos Consules, qui his impliciti sunt (ed. Maı et Zohr. p. 4). Auch vor dem Beginn der Lücke, die sich selbst auf den Anfang des Canons erstreckt, heisst es (c. 48, p. 218): iam vero operae pretıum erit his attexere Romanorum quoque post lul. Caesarem imperatores etc. Im Canon ist die Kaisergeschıchte zu düritig behandelt, und bei der Chronographie kōnnen wir uns auf die Uebersetzung des Hieronymus, der geflissentlich aus anderen Schriftstellern Zusătze macht, auch häufig aljkürzı, nicht mit Gewissheit verlassen. Nach der Beschaffenheit des Letzteren zu urtheilen, hat Zon. in diesem politischen Theile des Eusebius Clıronographie nur sehr beilăufig benutzen können.280 Die Vergleichung zeigt auch nur eine auffallende Uebereinstimmung, üler Diokletian's Stolz (s. Zon. p. 642 A cl. Hieronym. ed. Scalig. Amst. 1658, p. 47); allein gerade hier hat llieronymus ohne Zweifel den Eutrop. (IX. 16) berupft, wie diess auch Scaliger selbst erkennt (animadv. p. 244). Nun gibt aber dieser in der Restitution des griechischen Textes hăufig mehr als Hieronymus, so dass die Vergleichung sich erweitert. Unter den Fragmenten führt er hier, ohne Angabe der Quelle, ein sehr langes auf, über

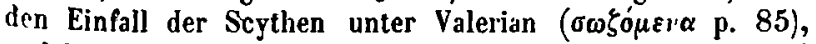
welches mit Zon. p. 629 C D, p. 630 A B fast durch und durch wörtlich übereinstimmt, nur dass Zon. eine abwei- 
chende Relation mitten hineinschiebt. Diess Fragment nun hat Scaliger augenscheinlich aus Georg. Syncell. (p. 381 sq. ed. Par.) herübergenommen und, da weder dieser auf Eusebius Bezug nimmt, noch Hieronymus ein solches Detail voraussetzen lāsst, wie mir scheint, ohne irgend einen hinreichenden Grund, so dass hier Eusebius nicht als Quelle des Zon. erscheinen darf.

281 Aber auch nicht eiumal Syncellus, wenigstens nicht ohne Einschränkung; denn obgleich Du Cange ihn ohne Weiteres für eine von dessen Quellen im Allgemeinen ausgibt (praef. ad not. hist.), uneingedenk des Umstandes, dass in ihm zum guten Theil der von Zon. sicher benutzte Eusebius verborgen ist, und obgleich bei der jetzigen Lückenhaftigkeit des Letzteren die Möglichkeit, dass Zon. einzelne Erweiterungen aus Syncellus herübergeholt, nicht abgelăugnet werden kaun: so streitet doch bei der fraglichen Erzăhlung gegen die Benutzung dieses Chronographen eben die von Zon. eingeflochtene abweichende Relation; mindestens muss er diese, die er voranstellt und für die beglaubigtere zu halten scheint, anderswoher halsen. Da aber überdiess in dem übereinstimmenden Theile hier wie dort sich dennoch einige isolirte und nicht unwesentliche Wendungen finden, so ist es am watürlichsten eine gemeinschaftliche Quelle zu muthmassen, die beide Relationen enthielt und aus der Jeder naeh Belieben Angaben und Worte borgte. Und diese gemeinschaftliche Quelle scheint mir keine andere, als der Contin. Dionis, um so melır, als der genũgsame Forschungsgeist, sowie die Bücherarmuth des Zon. so selten wie möglich an neue Richtungen und Seitenwege zu denken gebietet, und überdiess jener christliche Anonymus als ein sehr gangbarer, vielfach benutzter Autor sich darstellt. Dass er mit Ioannes Antiochenus identisch sei, wie Mai muthmasst (1. c. p. 234, nr. 1; vergl. jedoch p. 247, ur. 1), möchte ich entschieden bezweifeln, jedenfalls aber auf ihn alle sachliche Uebereinstimmungen und Anklänge zurückführen, welche etwa zwischen den Erzãhlungen des Zon. und denen des Dexippus, Eunapius, Zosimus, Päanius, Cedrenus und überhaupt aller derjenigen Schriftsteller, die 
Zon. durchaus nicht unmittelbar vor Augen gehabt zu habell scheint, obwalten; so-auch die interessante Erwăhnung ¿les Marcus und des Severus Hostilianus, die er nur mit Cedrenus gemein hat. Am bemerkbarsten sind naturgemäss die Anklănge an Zosimus, und ihrer mehrere finden sich in der That im Continuator Dionis wieder (s. dessen Fragmente a. a. 0., Mai's Anmerkungen, wo noch Manches zu ergănzen wăre, und die betreffenden Stellen im Zosimus). Völlig unhaltbar ist die Meinung, welche den Păanius zur Quelle des Zon. macht. Scaliger hat sie vielleicht zuerst282 ausgesprochen (animadv. ad Hieronym. p. 241, 244); auf ilın stützt sich Du Cange (ad Zon. praef. p. 6), und durch Schöll, der gar gleich den Eutrop substituirt (Gescl. d. gr. Lit. III. p. 247) und ohne Zweifel aus Du Cange's Vorrede schōpfte, ward der Irrthum allgemeiner verbreitet. Das einzige specielle Argument, worauf Du Cange fusst, ist die

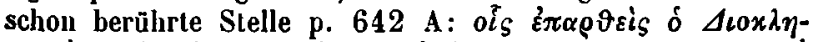

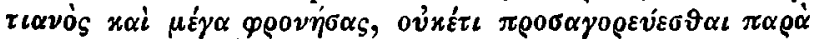

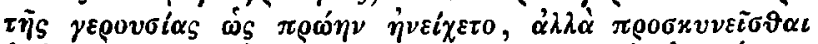

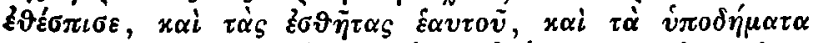

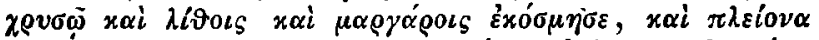

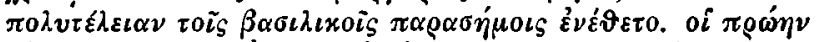

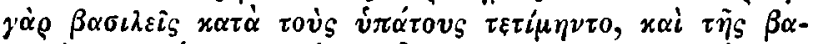

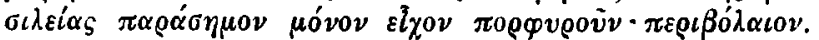
Hierzu bemerkt Jener p. 27 not. hist.: Paeanium hic exscripsit, ut alibi saepe, Zonaras; allein die Uebereinstimmung liegt nur in der allbekannten Thatsache und ist so wenig wörtlich, ja bietet so mannichfache Abweichungen, dass bei der knechtischen Weise des Zon. vielmehr die Nichtbenutzung daraus gefolgert werden muss. Bei Paeanjus lautet die Stelle nämlich (IX. 16, p. 176 ed. Kaltw.):

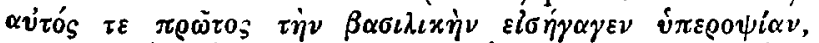

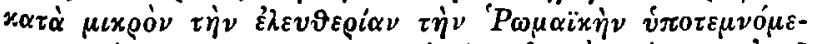

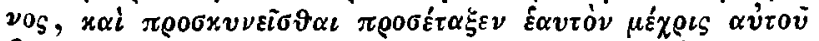

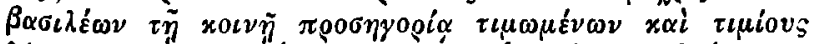

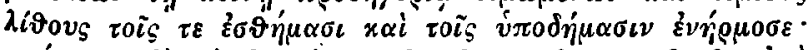

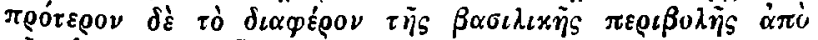

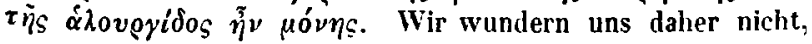


dass der Irrthum mit sich selbst in Opposition tritt, dass Scaliger mit glücklicherem Tacte wirklich gerade hier eine andere Quelle muthmasst (animadv. ad Hier. p. 244), und so Du Cange's einziges Argument durch den einzigen Gewährsmann, auf den er sieh beruft, selbst paralysirt wird. Dagegen meint Scaliger (l. c.), alles Uebrige, was Zonaras über Diocletian schreibe, sei von ihm aus Paeanius entnommen (s. Zonaras p. 640 A sqq. Paean. IX. 13 sqq.); Hoch es verhält sich hiermit in der That nicht anders, wie mit Du Cange's Beispiel: einzelne thatsăchliche und desshalb zum Theil wörtliche Uehereinstimmungen; dagegen bei $Z_{0}$. eine Menge von Erweiterungen im Delail und meist abweichende Diction. Der Punct, worauf sich Scaliger ausserdem stützt (an. p. 241: $\Gamma \alpha \lambda \alpha^{\prime} \tau \eta \nu$ eum [sc. Carum] vocat 283Zonaras ex Paeanio, quem ad verbum saepenumero sequitur), hat niclıt die geringste Beweiseskraft, und überdiess die bezũglichen Stellen Zon. p. $638 \mathrm{D}$, Paean. IX. 12 nicht eine entfernte Aehnlichkeit. Alle weitere Vergleichungen führen immer wieder $\mathrm{zu}$ demselben Resultate; beile Werke, schon in ihrer quantitativen Anlage so ganz verschieden, stehen durchaus in keiner directen Beziehung zu einander. Man sieht wohl, Zon. benutzt einen Autor, dessen Erzăhlungen mit denen des Eutrop. eine gewisse Quellenverwandtschaft haben, aber nicht die Uebersetzung des Eutrop. selbst; und immer wieder wird die Vermuthung auf deu detailreichen Anonymus zurückgeführt. Wie sehr sich dieselbe bei Allem, wo es auf Entscheidung ankommt, d. h. bei entlegenen Angaben und, soweit die spärlichen Excerpte reichen, hewährt, will ich schliesslich noch durch einige Beispiele erhärten: Ueber des Macrinus Fussübel Nov. Coll. Il. p. 235 cl. Zon. p. $632 \mathrm{C}$; über den Tod des Quintus in Emesa p. 239 cl. Zon. p. 633 B (dass Balistas beim Contin. nicht erwăhnt wird, ist Schuld des Eclogarius; angedeutet ist er aber in dem $x \alpha i \quad \delta \eta \lambda o \tilde{i} \alpha \dot{v} \tau o \tilde{i}_{S}$; über den Tod des Carinus p. 244 cl. Zon. p. 639 B (s. auch, obgleich diess Beispiel über die uns gesteckte Gränze hinausliegt, über Constantin's Absiclit, die Residenz nach Sardica zu verlegen, p. $246 \mathrm{cl}$. Zon. L. XIII. 3 init. T. II. p. 6 B). 
In dem kirchengeschichtlichen Theil folgt Zon. fast ausschliesslich dem Eusebius, den er auch mehrfach citirt (p. 620 B, 623 B, 627 A, 636 B, 644 B). s. Zon. p. 620 A med. - D med. cl. Euseb. hist. eccl. VI. 21, 2-

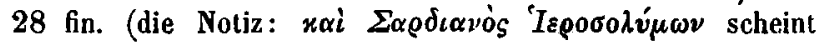
fast aus Synoellus p. 358 ed. Par. entlehnt; denn in der Kirchengeschichte des Eusebius VI. 10 lesen wir Tógdıos, in der armenischen Uebersetzung seines Kanons p. 387 Gurdianus. Dennoch schöpfte wohl, so scheint's, gerade hier Syncellus selbst aus Eusebius; Mai und Zohral, I. c. haben in dem aus ihm entlehnten griechischen Text $\Sigma \alpha \rho$ $\delta_{\iota \alpha \nu o_{S}}$ beibehalten, ebenso Scaliger in den $\sigma \omega \xi o \mu$. p. 84 . Die Abweichungen machen jede Entscheidung unsicher); (erner Zon. p. $623 \mathrm{~A}-\mathrm{C}$ fill. cl. Eus. H. eccl. VI. 23. 29

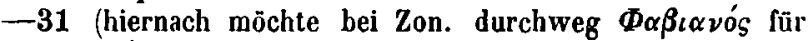

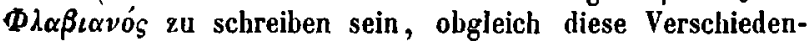
heit auch sonst besteht); Zon. p. $624 \mathrm{C}$ cl. Euseb. VI. 33; Znn. p. 625 C D cl. Eus. VI. 35. 39 (wo der neue Bischof von Antiochia $\Phi \dot{\alpha} \beta \iota \varsigma \varsigma$, nicht $\Phi \lambda_{\alpha} \beta \iota \alpha \nu o ́ s$, genannt wird; danach wăre auch Zou. p. $631 \mathrm{~B}$ zu corrigiren. Die Erwähnung des Cyprian findet sich bei Eusebius nicht im Zusammenhange, sondern VII. 3; Zon. schiebt ihn ein, neunt aber ebenso wenig wie Eusebius dessen Nachfolger. Die Jiatribe gegen Origenes p. 625 D vers. fin. - p. $626 \mathrm{D}$ ist selbststăndig); Zon. p. $626 \mathrm{D}-627 \mathrm{C}$ med. cl. Eus. VI. 43. 44 ; Zon. p. 629 B C cl. Eus. VI. 39, VII. 2.3. 5. 6 ; Zon. p. $631 \mathrm{~B}$ cl. Eus. VII. 14 cll. Vl. 35 . VII. 28 ; Zon. p. 634 D med. - $635 \mathrm{~A}$ vers. fin. cl. Eus. VIII. 27 -30 ; Zon. p. 636 C cl. Eus. VII. 30; Zon. p. 639 B med. -640 A med. cl. Eus. VII. 31 . 30 fin. 32 ; Zon. p. 642 A B cl. Eus. VIll. 2 sqq. - Der ausgedehnte Schluss des zwölften Buches von p. $646 \mathrm{~B}-648$ fin., die Reihenfolgen der Bischöfe von der Zeit des Marcellinus an enthaltend, findet weder in der Kirchengeschichte, noch in284 der Chronik des Eusebius, wie es scheint, ihren Halt; die Quelle ist wegen des vielbehandelteu Gegenstandes nicht mit Gewissheit anzugeben. Dass übrigens Zon. die Kirchengeschichte des Eusebius auch bei politischen Ereignissen zu 
Rathe zog, beweist p. 644 B, wodurch zugleich ausser Zweifel gestellt wird, dass der Appendix I wirklich als ein integrirender Theil des achten Buches auch damals galt; denn auf seinen Inhalt bezieht sich das Citat des Zon., und dieser gibt das achte Buch ausdrūcklich an.

Ich reihe noch einige aphoristische Bemerkungen an die vorstehende Untersuchung.

Lateinische Autoren hat Zon. nicht benulzt. Daraus, dass er die Zeit von den Gracchen bis auf Cäsar, aus Mangel an Büchern, wie er sagt, übergeht, ersieht man mit Gewissheit, dass auch die griechische Uebersetzung des Sallust von Zenobius oder Zenodotus ihm nicht zur Hand war; ebenso mussten ihm ausser Appian aus diesem Grunde auch Posidonius, Iuba, Diodor, Nicolaus Damascenus, Iustus von Tiberias und viele Andere mangeln, der endlosen Reihe der Specialschriftsteller gar nicht einmal zu gedenkeu.

Die Arbeit des Zon., als eine Art von Lehrbuch auf blosse Abschreiberei und Zusammenstellung basirt, ist schon desshalb an Bedeutung für die Wissenschaft ebenso nichtig, wie Tausende von Compendien der neueren Zeit. Jedenfalls können wir nach dieser Section der ersten zwölf Bücher die singularis eruditio nicht finden, welche Du Cange (praef.) an ihm lobt; Zon. ist wegen seines zufälligen relativen Werthes in seinem inneren und absoluten noch immer bei weitem überschätzt worden. Nicht wenig trug hierzu auch die Vorliebe bei, welche die Editoren so gewöhnlich fūr ihren Autor hegen. Diess zeigt sich unter Anderem auch jn Du Cange's durchaus schiefer und mit Widersprüchen angefüllter Apologie (s. praef.) gegen die richtige Behauptung des Gerardus Vossius. Ein Princip, das man häufiger aufgibt, als anwendet, kann in keinem Puncte als rechtfertigendes Motiv vorgeschoben werden. Zur Zeit der beiden ersten Herausgeber war die historische Wissenschaft noch nicht im Schwunge; sie selbst waren mehr Philologen als Geschichtsforscher, und man darf es ihnen daher nicht allzu hoch anrechnen, wenı sie eines Zonaras conatum egregium atque institutum praeclarum preisen, in ihm zu finden ver- 
meinen, was dessen Freunde in ihm suchten, und ihn mit Lobsprüchen überhăufen, denen wir vom heutigen Standpuncte aus auf das entschiedenste entgegentreten müssen, ohne Besorgniss, dass uns die oratorischen Blitze treffen kŏnnten, welche Hieronymus Wolf gegen die morosos und obtrectatores schleudert (in der praef. zu seiner Edítion). Sein Eifer ist. rühmlich, seine Worte schön und an sich wahr: morosorum vero, ruft er aus, et obtrectatorum querelas atque aculeos quis hominum deorumve effugial? quibus, nisi quod ipsi fecerunt, nihil placet. Nur schade, dass sie auf den simius Dionis, um mit Mai zu sprechen, gerade auf den Autor keine Anwendung finden, auf welchen er sie anzuwendeu so ausführlich bemūht ist, - als der wūrdige Patron eines unwūrdigen Clienten; seinc Liebe ist mehr officiell als gerecht. Unser Urtheil aber, das die rein objective Betrachtung zur inmersten Ueberzeugung bildete, dür-285 fen die christlich bescheidenen Worte nicht mehr umstimmen, mit denen Zonaras das Werk seiner Musse schliesst. (T. II. p. 311.)

Die Gelehrsamkeit, welche das dem Zonaras zugeschriebene Lexikon zur Schau trägt, ist ebenfalls nur eine beschrănkte zu nenmen; auch hier ist aus ein Paar Büchern ein neues zusammengetragen. Wir begnũgen uns eine $\mathrm{Be}$ merkung Mai's darūber mitzutheilen (Nov. Coll. Il. p. 566): quamquam Zonaras in historia sua simius Dionis fuit, nihil ille tamen ex huius historia habet in lexico, quod ex Suidae potius promptuario sumptum non videalur. Quamobrem vel lexici auctor non est Zonaras, vel is certe ante lectum Dionem lexicographus fuit.

Bei einer neuen Ausgabe der Annalen des Zonaras bleibt noch erstaunlich viel zu leisten. Mit Zuversicht dürfen wir erwarten, dass der Herausgeber derselben für das Bonmer Corpus Byz., der rūhmlichst bekannte und thãtige Dr. Pinder, sich ein unvergãngliches Verdienst um ihn erwerben werde. Ein sorgfăltiger Commentar ist, nicht minder wie eine behutsame Constitution des Textes, eins der Haupterfordernisse. Du Cange freilich erk]ărt einen genauen Commentar ülser die Einzelheiten für üherflüssig (praef. ad not. 
hist.); bei solcher Ansicht kann es uns aber nicht wundern, wenn er, wenigstens beim ersten Theil, für das kritische und historische Moment so wenig oder vielmehr Nichts leistet. Er hat keine vertraute Bekanntschaft mit seinem Autor geschlossen, und wenn er daher gar einmal einen kritischen Griff versucht, so ist es gewöhulich ein ein Fehlgriff. Dahin gehört es, wenn er dem Zonaras zuversichtlich einen Philo und Paeanius als Quellen andichtet, wo derselbe in Wahrheit ganz andere Schriftsteller, wie die Kirchengeschichte des Euselius, benutzte.

Bringt man nun eben in Anschlag, wie wenig die bisherigen Herausgeber dieses Feld der Forschung berügksichtigt, und wie sie sogar durch Verkennung der Kriterien und hierdurch veranlasste Missgriffe nur dazu beigetragen, dasselbe zu trüben und zu verwirren: dann dürfte wohl die zum erstenmal unternommene Sichtung eines von den Historikern bis auf die neveste Zeit herab meist ganz vernachlässigten oder ohne Urtheil gehandhabten Autors nicht als unnütz erscheinen, noch Leistung und Ansbeute, wie gering sie auch sein mögen, völlig verschmahet werden. Nach Vollständigkeit rang ich nicht; auch berührte ich selten, was dem eigentlichen $Z$ wecke fern lag. Unzăhlige philologische und historische Berichtigungen mussten kūnftigen Herausgebern und Geschichtschreibern üherlassen bleiben; ich meinerseits durfte nur andeuten, nicht durchweg commentiren. 